\title{
Longitudinal Trajectory of Early Functional Recovery in Patients with First Episode
}

\section{Psychosis}

Mei-Hua Hall ${ }^{1}$, Kristina M Holton ${ }^{2}$, Dost Öngu $\square r^{1}$, Debra Montrose ${ }^{3}$, Matcheri S. Keshavan

${ }^{1}$ Psychotic Disorders Division, McLean Hospital HMS, Boston, MA,

${ }^{2}$ Department of Research Computing, HMS, Boston, MA,

${ }^{3}$ Western Psychiatric Institute and Clinic, University of Pittsburgh School of Medicine, Department of Psychiatry, Pittsburgh, PA,

${ }^{4}$ Beth Israel Deaconess Medical Center and Massachusetts Mental Health Center, HMS, Boston, MA

Address for correspondence:

Mei-Hua Hall, Ph.D.

Psychosis Neurobiology Laboratory, Mailstop 315, Harvard Medical School, McLean Hospital, 115 Mill Street, Belmont, MA 02478 USA; Tel: 617-855-3632

E-mail: mhall@mclean.harvard.edu

Word count text: 3981

Abstract: 250

Number of tables: 4 
bioRxiv preprint doi: https://doi.org/10.1101/525824; this version posted January 21,2019 . The copyright holder for this preprint (which was not certified by peer review) is the author/funder. All rights reserved. No reuse allowed without permission.

Number of figures: 3

Supplementary table: 2

Supplementary figures: 3

Keywords: Functional Recovery, K means clustering, outcome trajectories, First Episode

Psychosis, Longitudinal study 


\section{Background:}

There is a large variability in the recovery trajectory and outcome of first episode of psychosis [FEP] patients. To date, individuals' outcome trajectories at early stage of illness and potential risk factors associated with a poor outcome trajectory are largely unknown. This study aims to apply three separate predictors (positive symptoms, negative symptoms, and soft neurological signs) to identify homogeneous function outcome trajectories in patients with FEP using objective data-driven methods, and to explore the potential risk /protective factors associated with each trajectory.

\section{Methods:}

A total of 369 first episode patients (93\% antipsychotic naive) were included in the baseline assessments and followed-up at 4-8 weeks, 6 months, and 1 year. $\mathrm{K}$ means cluster modelling for longitudinal data $(\mathrm{kml3d})$ was used to identify distinct, homogeneous clusters of functional outcome trajectories. Patients with at least 3 assessments were included in the trajectory analyses ( $\mathrm{N}=129)$. The Scale for the Assessment of Negative Symptoms (SANS), Scale for the Assessment of Positive Symptoms (SAPS), and Neurological examination abnormalities (NEA) were used as predictors against Global Assessment of Functioning Scale (GAF).

\section{Results:}

In each of the three predictor models, four distinct functional outcome trajectories emerged: "Poor", "Intermediate", "Good" and "Catch-up". Individuals with male gender; ethnic minority status; low premorbid adjustment; low executive function/IQ, low SES, personality disorder, substance use history may be risk factors for poor recovery. 
bioRxiv preprint doi: https://doi.org/10.1101/525824; this version posted January 21,2019 . The copyright holder for this preprint (which was not certified by peer review) is the author/funder. All rights reserved. No reuse allowed without permission.

\section{Conclusions:}

Functioning recovery in individuals with FEP is heterogeneous, although distinct recovery profiles are apparent. Data-driven trajectory analysis can facilitate better characterization of individual longitudinal patterns of functioning recovery. 


\section{Introduction}

Clinical presentations of first episode psychosis are heterogeneous (Keshavan et al., 2013). Patients with a first episode of psychosis [FEP] frequently present with a mixture of affective and psychotic symptoms, making it often difficult to make a definitive diagnosis. About a third of FEP patients receive diagnoses of affective psychosis at the end of two years and about two thirds receive a diagnosis of schizophrenia [SZ] (Keshavan and Schooler, 1992). Moreover, psychotic spectrum disorders such SZ, schizoaffective [SA], and psychotic bipolar disorder [BPD] have substantial overlap in symptoms, neurobiology, treatment response, and genetic liability (Cross-Disorder Group of the Psychiatric Genomics et al., 2013a; Cross-Disorder Group of the Psychiatric Genomics et al., 2013b; Hall and Smoller, 2009; Hall et al., 2015; Hall et al., 2013; Hall et al., 2009; Hill et al., 2013; Ivleva et al., 2012; Mathew et al., 2014; Ruderfer et al., 2014; Sklar et al., 2011; Tamminga et al., 2014). This heterogeneity is likely caused by multiple etiologies such that psychosis is likely a final common endpoint, similar to 'congestive heart failure' being a common endpoint of cardiac, renal and pulmonary diseases, each of which requires different optimal treatment strategies.

Psychotic disorders are accompanying by prominent social and occupational functional impairment, and represent as one of the leading causes of disability worldwide (Global Burden of Disease Study, 2015). Functional deterioration occurs at the fastest rate during the early phase of psychosis (Cannon et al., 2015; Jindal and Keshavan, 2008; Pantelis et al., 2005), which is both a "critical period" of neuronal and psychosocial plasticity and a "window of opportunity" during which treatment may confer disproportionately favorable outcomes(Caplan 
et al., 2013; Dazzan et al., 2015; Flyckt et al., 2006). In FEP patients, there is a large variability in the recovery trajectory and functional outcome (Allott et al., 2011; Menezes et al., 2006;

Robinson et al., 2004; Strauss et al., 2010). Only $26-43 \%$ of FEP patients are estimated to achieve good global functional outcome at 1-2-year follow-up (Gonzalez-Blanch et al., 2010; Menezes et al., 2006). About $10-15 \%$ of FEP patients are highly treatment resistant. While the majority of the patients have symptomatic recovery (Verma et al., 2012) a subgroup of patients experience multiple relapses during the course of illness (Lehman et al., 2004). Also, individuals treated with antipsychotic medications may achieve good symptomatic outcomes, but have significant persistent functional disabilities, particularly in vocational and social domains (Gupta et al., 1997; Hegarty et al., 1994; Robinson et al., 2004; Tohen et al., 2000). This variability is likely due to the fact that functional recovery represents a multi-dimensional construct and many distinct domains of neurobiological alterations collectively contribute to the variance in functioning (Allott et al., 2011).

According to the literature, severity of psychopathology, particularly negative symptoms (Carlson et al., 2012; Herbener and Harrow, 2004; Ho et al., 1998; McGlashan and Fenton, 1992; Smith et al., 2002; Ventura et al., 2009), neurocognitive impairments (Best et al., 2014; Bowie et al., 2010; Green et al., 2000), and premorbid characteristics (Ayesa-Arriola et al., 2016; Bucci et al., 2016) are significant and independent predictors of functional outcome, although the role of positive symptom as a predictor of functional outcome is inconsistent in the literature (Green, 1996; Green et al., 2000). In addition, neurological examination abnormalities (NEA), which are subtle neurological abnormalities comprising impairments in motor function and sensory integration, and persistence of primitive reflexes, have been documented in first 
episode antipsychotic naïve patients (Sanders et al., 1994; Venkatasubramanian et al., 2003b) and patients with psychosis or BPD (Arabzadeh et al., 2014; Bora et al., 2018; Fountoulakis et al., 2018). NEA and the pathophysiology of schizophrenia may share a common genetic liability that affects the neurodevelopmental trajectory of this illness (Chan et al., 2009; Prasad et al., 2009).

Identifying individuals' outcome trajectories at early stage of illness and potential risk factors associated with a poor outcome trajectory are of high priority because this knowledge can guide the development of individually tailored treatment and effective interventions that potentially alter the course of the disease. Many previous studies of functional outcome are limited by possible confounding factors, including prior use of neuroleptic medications (Arnold et al., 2015; Chakos et al., 1994; Keshavan et al., 1994) or illness chronicity (Schwarzkopf et al., 1990). Studies of first-episode, never treated patients can address these confounds. Also, most studies investigating functional outcomes start with clinical categorization and compare outcomes between different diagnostic groups, rather than relying on objective data driven approaches. Furthermore, when thinking about potential interventions, relatively few studies have considered potential socio-economic and personality characteristics between outcome trajectories. However, such analyses can help better understand the differences between trajectories and identify potential intervenable factors, such as substance use, that could be of interest to public policy.

Studies have applied unsupervised methods as exploratory tools to identify trajectory classes within the data. Statistical methods used to determine homogeneous group trajectories can be 
separated into two families. The first comprises model-based methods. These are related to mixture modelling techniques or latent class analysis, such as Group-Based Trajectory Modeling (Nagin and Odgers, 2010), growth mixture modeling (GMM) (Curran et al., 2010; Muth'en, 2004). Three recent reports have used GMM analysis examining patterns and predictors of trajectories for social and occupational functioning in FEP patients. Hodgekins et al. (2015) examined social recovery profile of FEP patients over 1-year period and found that male gender, younger age at onset of psychosis, more severe negative symptoms at baseline and poorer premorbid adjustment predicted poor recovery trajectory (Hodgekins et al., 2015). Velthorst et al. (2016) investigated long-term 20-year trajectories of social impairment in firstadmission psychosis patients and identified four distinct but stable trajectories of social functional outcomes (Velthorst et al., 2016). Chang et al. (2018) investigated the socialoccupational functional trajectories in Chinese FEP cohort over 3 years. The authors also found four distinct functional trajectories and that male gender, lower educational attainment, diagnosis of schizophrenia-spectrum disorders, as well as hospitalization upon first psychosis breakdown were associated with poor functional recovery. One essential step of growth models is the identification of the optimal functional form of the trajectory over time using the mean and covariance structure of the data, that is, the shape of the latent trajectories is specified in advance to fit a particular functional form of growth and formal tests are used to evaluate the fitness of the hypothesized model. As such, growth modeling approaches try to model trajectories and the group trajectories being theoretical constructs defined to take into account the heterogeneity in the data. 
The second group of approaches relates to machine learning partitional classification analysis, such as K means clustering (Genolini and Falissard, 2010). The k-means algorithm uses variance distances or dissimilarity metrics such as the Euclidean distance metric between curves to identify and classify trajectories. The k-means algorithm corresponds to a nonparametric classification method: it searches the classification of the data that minimizes a specific within-group distance metric. The $\mathrm{K}$ means cluster modelling for longitudinal data $(\mathrm{KmL})$ is thus an alternative classification to mixture modeling (Genolini and Falissard, 2011; Genolini et al., 2013; Subtil et al., 2017). Some potential advantages of k-means method are that: it is a non-parametric hill-climbing algorithm, does not impose assumptions regarding normality or the parameterization within the clusters or the shape of the trajectories, is likely to be more robust as regards numerical convergence, and is robust against mis-specification of model. The ability to classify outcome categories at an individual level is also likely to facilitate personalized approach to prediction and treatment. Although $\mathrm{KmL}$ approach has been used in biomedical studies to define clusters of patients with homogeneous trajectories of change (Pingault et al., 2013), or treatment response over time (Honer et al., 2015), to our knowledge, no report has applied objective data-driven $\mathrm{KmL}$ approach to identify homogeneous trajectories of functional outcome in patients with first episode psychosis (minimally treated with antipsychotics at study entry). Therefore, the primary aim of the study was to use unsupervised machine learning $\mathrm{KmL}$ method to empirically derive functional outcome trajectories of three core phenotypes (positive symptoms, negative symptoms, and NEA) in primarily unmedicated FEP patient cohort. Since the task was to cluster data on which no a priori hypothesis is available, and consequently would prefer to avoid the issues related to model selection using model-based procedures, the use of $\mathrm{K}$ means clustering is appropriate. 
The second aim was to characterize the socio-economic, personality, executive function, and clinical profiles of patients in each trajectory, in order to identify potentially modifiable processes or risk factors in FEP correlated with these different trajectories.

\section{Methods}

Subjects: Data were collected between 1996 and 2004 from The Pittsburgh First Episode of Psychosis (FEP) Longitudinal Cohort Study) (Keshavan et al., 1998). Patients were recruited from the inpatient and outpatient services of the Western Psychiatric Institute and Clinic, Pittsburgh. Patients with previously untreated psychosis were evaluated by trained clinicians using the Structured Clinical Interview for DSM-IV (SCID). Patients were included in the study if they were aged $15-45$, had an IQ $>75$, met the DSM-IV criteria for a psychotic disorder, and had no or minimal prior treatment with neuroleptics, no significant medical or neurological illness, no history of head injury with loss of consciousness temporally related to psychosis onset, and no current substance abuse or dependence. DSM-IV diagnoses were derived in consensus diagnostic evaluations by the raters and senior MD or $\mathrm{PhD}$ level clinicians on the basis of all available clinical data and the SCID-P interview data. A total of 369 first episode patients (93\% antipsychotic naive) with schizophrenia (SZ) $(n=221)$ or non-SZ psychoses $(n=$ 144) were included in the baseline assessments. At study entry, patients who had received more than 2 weeks (in their lifetimes) of antipsychotic treatment were excluded. Patients were followed up at 4-8 weeks, 6-months, and one-year time point and treated with standard antipsychotic medications and supportive individual and/ or group psychotherapy in community treatment programs. The design, recruitment process and samples have been described in 
detail elsewhere (Keshavan et al., 2003; Li et al., 2011; Prasad et al., 2005). Patient socialdemographic characteristics, clinical evaluation, and phenotypic assessments (described below) were recorded at each point.

\section{Clinical and phenotype assessments:}

Duration of Untreated IIIness (DUI) was assessed in each case by the same raters using all clinical information, including medical records, reports by family members or significant others, and SCID interviews. The most likely date of illness onset, as defined by the onset of prodromal positive or negative symptoms, was then determined in consensus diagnostic conferences.

Psychopathological ratings were carried out by trained raters who also participated in the diagnostic meetings described above. Illness severity was assessed using the Global Assessment of Function (GAF) scale (Aas, 2010). GAF scores at 4-8 weeks, following stabilization of acute psychotic symptoms, were taken to reflect baseline level of functioning. Positive and negative symptoms were measured, respectively, using the Scale for the Assessment of Positive Symptoms (SAPS) and the Scale for the Assessment of Negative Symptoms (SANS) (Andreasen et al., 1990). General psychopathology symptoms were rated using the affective items from the Brief Psychiatric Rating Scale (Overall and Gorham, 1962) and the 24-item Hamilton Rating Scale for Depression (Hamilton, 1960). Scales were scored by averaging across items to produce an average rating for each of the symptom domains assessed. Ratings were conducted by trained and reliable (Kappa >.5) raters. Premorbid 
academic and social functioning were assessed using the Premorbid Adjustment Scale (PAS: (Cannon-Spoor et al., 1982) and were examined from childhood through late adolescence (Allen et al., 2001; Cannon et al., 1997).

Neurological examination abnormalities (NEA), also called neurological "soft" signs (NSS), were evaluated using the modified Buchanan-Heinrichs scale (Buchanan and Heinrichs, 1989; Sanders et al., 2006). NSS abnormality is predictive of neuropsychological performance in first episode psychosis (Arabzadeh et al., 2014; Mohr et al., 2003) and in chronic schizophrenic patients (Sewell et al., 2010), and is correlated with treatment response and recovery outcome (Prikryl et al., 2007). Our previous principal components analyses (Sanders et al., 2000; Venkatasubramanian et al., 2003b) revealed two dominant factors: repetitive motor sequencing (including fist-ring, alternating fist-palm, and rapid alternating movements) and cognitively demanding perceptual tasks (dominated by sensory/ audiovisual integration). The cognitive/perceptual neurological abnormalities factor correlates with neuroanatomical alterations and with neuropsychological assessments that tap into executive function and memory (Arabzadeh et al., 2014; Venkatasubramanian et al., 2003a). Studies also found a significant link from NSS to specific neurocognitive deficits (e.g., executive attention, verbal memory, and visual memory) and that more evidence of NSS is associated with more severe impairments in executive and memory functions, which are significant predators of functional outcomes(Arango et al., 1999). Given that functional outcome is of primary interest to the present study and given the evidence of significant relationships between NSS and executive function as well as between cognitive function and functional outcomes, we investigated the cognitive/perceptual neurological score in the analyses. 
Personality assessments were carried out by a trained clinician (Keshavan et al., 2005). The Personality Disorder Evaluation, a semi-structured instrument (Loranger et al., 1991), was used and grouped personality dimensions into three main clusters, namely Cluster A (Paranoid, Schizoid, Schizotypal), Cluster B (Antisocial, Borderline, Histrionic, Narcissistic), and Cluster C (Avoidant, Dependent, Obsessive-compulsive) (Lenzenweger, 1999; Lenzenweger et al., 2007; Lenzenweger et al., 1997). The assessments were typically carried out before the consensus diagnostic conferences were held; the clinician was therefore unaware of the consensus diagnoses at the time of the personality assessment.

Executive functions were evaluated using the Wisconsin Card Sorting Test by a trained psychologist (WCST, Computerized Version 4.0)). Multiple categories were collected in this task but they are highly correlated. We selected number of perseverative errors as the main measure of executive function. Estimated premorbid IQ was assessed using the Ammon's quick IQ test(Ammons and Ammons, 1962)

\section{Statistical analysis}

\section{Cluster Trajectory Analysis}

$\mathrm{K}$ means cluster modelling for longitudinal data (K-means longitudinal 3D ( $\mathrm{kml3d}$ ), $<$ http://CRAN.R-project.org/package=km|3d >), was used to identify distinct, homogeneous clusters of functional outcome trajectories over 4 assessment time points (baseline, 4-8 weeks, 6 month, 12 month). Because this study included three independent predictors (SAPS, SANS, 
NEA), three sets of two variable pairs (SAPS-GAF, SANS-GAF, NEA-GAF) k means clustering were performed in kml3d over 4 time points, enabling to study the joint evolution or complex interactions between variables over time (Genolini et al., 2015; Genolini et al., 2013). In addition, $\mathrm{km} / 3 \mathrm{~d}$ provides tools to visualize 3D dynamic graphs which can be exported in a 3D dynamic PDF. This visualization enables a better representation of the interaction between the two variable-trajectories. $\mathrm{KmL}$ provides substantially greater predictive power than single variable-trajectory (Shah et al., 2012) and is as efficient as the existing parametric algorithm on polynomial data, and is potentially more efficient on non-polynomial data (Genolini \& Falissard, 2010). To evaluate the optimal number of cluster trajectories, we tested a number of models with different number of cluster trajectories (see supplementary material). Each model was repeatedly fitted with the number of clusters increasing step-wise from 2 to 6 using maximum likelihood criterion, computed using the KmL3D algorithm. We assessed model fit by using i) the Sum of Squared Error (SSE) within each cluster, ii) SSE between clusters, and iii) the Partitioning Around Mediods (PAM) method to measure how well individuals belong to a cluster trajectory and by using scree plots to visualize an "elbow," or point representing the optimal number of clusters.

Patients with at least 3 assessment time points were retained in the analyses $(\mathrm{N}=129)$. The SAPS, SANS, and NEA cognitive/perceptual neurological score were used as the main predictors against the GAF score as the functioning outcome measure over 4 assessment time points. $\mathrm{kml3d}$ provides tools to visualize 3D dynamic graphs Missing values were imputed by carrying the last observation forward. Each of the three predictors (SANS, SAPS, NEA) was jointed with functional outcome variable GAF to derive functional trajectories in three separate 
analyses.

Once patients were assigned to specific trajectory groups, baseline information including demographics (sex, race, SES, IQ), executive function (WCST Number of perseverative errors), personality, and clinical features (diagnosis, histories of substance use, age of onset, premorbid function, duration of prodromal symptoms, brief psychotic rating Score, Hamilton rating scale for depression) were used to characterize each trajectory profile and to identify potential risk or protective factors for poor and good functional trajectories, respectively. ANOVA, t-test and $\mathrm{x} 2$ tests were used to compare between and within trajectory groups.

\section{Results}

A total of 369 patients were assessed in the baseline. Among them, 129 patients (SZ $n=82 \&$ non-SZ psychoses $n=47$ ) with at least 3 assessment data points were included in the $\mathrm{kml} 3 \mathrm{~d}$ analyses. Characteristics of the baseline sample and those who were included in the $\mathrm{kml} 3 \mathrm{~d}$ analyses were presented in Table 1. There were no significant differences between the two groups (Table 1).

\section{Trajectory Identification}

The four-trajectory solution was chosen as the best fit as this solution was the most consistent and captured cohesiveness and separation better than others (see supplementary material for detail and Figure S1 \& S2). We labelled these four distinct functioning trajectories as "Poor 
Outcome", "Middle Outcome", "Good Outcome" and "Catch-up". Patients in the good-outcome trajectory exhibited mild symptoms at baseline and the highest functioning a year later, whereas those in the poor-outcome trajectory had the most severe symptoms at baseline and recovered poorly a year later. Patients in the catch-up trajectory exhibited severe symptoms at baseline, indistinguishable to the poor-outcome patients, but were able to catch up in recovery to achieve good functioning a year later. Finally, patients in the middle-outcome trajectory showed moderate symptoms at baseline and partial functioning recovery a year later. The demographic and clinical characteristics of each trajectory and statistical comparisons between Good and Poor outcomes are presented in Table 2-4. Comparisons among other groups are presented in the Supplementary Materials. We provide an online file which allows the reader to explore the three-dimensional trajectories in a dynamic fashion ( $<k m|3 d . s a p s . h t m l>k m| 3 d . s a n s . h t m l><k m l 3 d$.nes.html $>$.

\section{SANS as Predictor of Functioning Trajectories}

Patients in the good-outcome trajectory (Table 2, Figure 1, Purple color [D]) had the highest premorbid IQ score and parental SES but the lowest age of psychotic symptom onset, BPRS and HRSM scores, premorbid childhood abnormalities and personality cluster A traits. They were the least likely to use substances than patients in the other trajectories. Patients in the Catch-up trajectory (Figure 1, Cyan color [C]) were predominately diagnosed with SZ and were more likely to be Caucasian. They share similar characteristics with good-outcome patients in terms of SES, IQ, low personality cluster A traits, and low substance use, but differed in terms of psychotic symptom age onset, HRSM scores, and childhood premorbid abnormalities. 
Patients in the middle-outcome trajectory (Figure 1, Green [B]) were more likely to have affective psychosis (62\%) diagnosis. These patients performed well (fewest errors) on WCST. Patients in the poor-outcome trajectory (Figure 1, Red $[\mathrm{A}]$ ) were primarily diagnosed with SZ and more likely to be male. These patients had the lowest IQ score and came from lower SES strata. In addition to severe negative symptoms, they also exhibited high premorbid abnormalities, high personality cluster A and C traits, performed the worst in WCST, and used substance the most than patients in the other trajectories (also see $<\mathrm{kml} 3 \mathrm{~d}$.sans.html $>$ ).

ANOVA results showed significant group differences in the distribution of diagnoses, race, IQ, BPRS score, substance use history, and personality trait. Patients in the good outcome trajectory had more evenly distributed diagnosis, more Caucasian, higher IQ, lower psychotic (BPRS) symptoms, and lower Cluster B personality trait (Antisocial, Borderline, Histrionic, Narcissistic) than those in the poor trajectory group (Table 2).

\section{SAPS as Predictor of Functioning Trajectories}

Patients in the good-outcome trajectory (Table 3, Figure 2, Green color [B]) were more likely to be Caucasian (66\%), had higher IQ score, parental SES, and premorbid function and lower BPRS and HRSM scores, personality cluster A traits, and used substance less than patients in the other trajectories. Patients in the Catch-up Trajectory (Figure 2, Cyan color [C]) were predominately diagnosed with SZ. They had higher personal SES and HRSM score, older psychotic symptom onset, and lower personality cluster B traits than patients in the other trajectories. Patients in the poor-outcome trajectory (Figure 2, Purple color [D]) were primarily 
diagnosed with SZ (86\%), more likely to be male (81\%) or African American (57\%), a lower IQ score and came from lower SES strata. They also exhibited high personality cluster B traits, performed the worst in WCST task, and used substances the most than patients in the other trajectories.

Significant group differences were fund between good and poor outcome trajectory in the distribution of diagnoses, IQ, patent SES, BPRS, and personality cluster A traits. Patients in the good outcome trajectory had more evenly distributed diagnosis, were more often Caucasian had higher IQ, lower psychotic (BPRS), and lower depression and anxiety (HRSM) symptoms than those in the poor trajectory group (Table 3).

\section{NEA (NSS) as Predictor of Functioning Trajectory}

Consistent with results obtained from SANS and SAPS, good-outcome patients (Figure 3, Red color $[A])$ were more likely to be Caucasian, had higher IQ score and SES, performed well on WCST, and used substances the least than patients in the other trajectories. Patients in the catch-up trajectory (Figure 3, Cyan color [C]) were predominately diagnosed with SZ and were more likely to be Caucasian, had higher premorbid function, lower age onset, lower personality A and $\mathrm{C}$ traits than patients in the other trajectories. Patients in the poor-outcome trajectory (Figure 3, Purple [D]) were primarily diagnosed with SZ (86\%), more likely to be male (74\%), had lower IQ, performed poorly on WCST, came from lower SES strata, and were used substance the most than patients in the other trajectories. 
Significant group differences were found in the distribution of diagnoses, IQ, parent SES, and BPRS. The good outcome trajectory had more evenly distributed diagnosis, higher IQ, and lower psychotic (BPRS) than those in the poor trajectory group (Table 4).

\section{Discussion}

In this study, we employed machine learning unsupervised $\mathrm{kml3d}$ clustering methods to derive distinct, homogeneous clusters of short-term functional outcome trajectories in a sample of patients with FEP. These patients were antipsychotic-naïve or minimally antipsychotic-treated at study entry and were longitudinally followed at 4-8 weeks, 6 months and 12 months later. Three core phenotypes were used, each as an independent predictor in separate kml3d models, to examine the joint trajectories of each predictor with functional outcome. To preserve a larger sample size and minimize the influence of imputation on the results (i.e., more accurate standard error estimates) (Twisk and de Vente, 2002), we included only patients with at least 3 assessment time points rather than imputing all the missing data in the $\mathrm{kml} 3 \mathrm{~d}$ analyses. Although there have been many studies of outcome in SZ (Carpenter and Kirkpatrick, 1988; Levine et al., 2011), few have used a data driven approach to empirically detect distinct outcome trajectories while capturing the longitudinal course of functional levels across the entire study period. Trajectory analysis is a useful strategy to reduce heterogeneity and provide insight into clinically meaningful subgroups of patients (Honer et al., 2015).

Results indicated that a four-cluster trajectory was the best fit. Importantly, the four trajectories identified in each predictor model are highly consistent and concordant in terms of the overall profiles (trajectory shapes), patterns, and the sample characteristics. We labelled the 4 distinct functional recovery trajectories as: (1) Good Outcome-- individuals had the mildest symptoms 
or neurological abnormality at study entry and recovered well to achieve the highest functioning a year later; (2) Poor Outcome-- individuals had the most severe symptoms or neurological abnormality at study entry and recovered poorly to achieve the lowest functioning a year later; (3) Intermediate Outcome -- individuals had moderate symptoms or neurological abnormality at study entry and recovered to achieve intermediate level of functioning a year later; (4) Catch-up-- individuals had severe symptoms or neurological abnormality at study entry but were able to "catch-up" in recovery a year later to achieve global functioning level similar to individuals in the good outcome trajectory.

The Catch-up Outcome trajectory is the most intriguing. At the study entry, individuals in the Catch-up trajectory were indistinguishable from those in the Poor Outcome trajectory, exhibiting severe positive and negative symptoms and cognitive/perceptual neurological abnormality. However, the recovery path was very different. Patients in the Catch-up trajectory were able to recover quickly and to achieve functioning level akin to those in the good-outcome a year later (at 12-month follow-up Poor: GAF score between 38.8 and 45.5; Catch-up: GAF score between 56.3 and 62.3). In addition, the Catch-up trajectory consistently emerged in each predictor model. The characteristics of individuals in the Catch-up trajectory appear to be more female, Caucasian, having higher IQ, higher executive function, having better premorbid adjustment, coming from higher socio-economic background, as well as having less substance use history as compared with individuals in the Poor Outcome trajectory. These differences in characteristics between Poor and Catch-up were robustly consistent across all three predictor models.

On the other hand, across all three models patients in the Good Outcome and Catch-up appear to share similar socio-economic and cognitive function profile, such that patients with 
good outcome were also more likely to be female, Caucasian, having higher IQ and higher executive function, having lower psychopathology and personality cluster A (Paranoid, Schizoid, Schizotypal) traits, coming from higher socio-economic background, as well as having less substance use history than those in the Poor trajectory.

In our study, the same diagnoses did not have a strong predictive value for the different trajectories. A majority of individuals in the Poor Outcome and Catch-up trajectories have diagnosis of SZ, whereas patients in the Good Outcome and Middle trajectories include both SZ and affective psychosis. Biologically based phenotypes at baseline may allow better predictions (Clementz et al., 2016; Hall et al., 2012). Many clinical and neurobiological alterations collectively contribute to variance in functioning (Allott et al., 2011). Our results showed that multivariate models that integrate diverse domains of risk predictors at baseline can identify neurobiologically homogeneous sub-groups, which provide substantially greater predictive power for functional trajectory.

Our results suggest that being male, being an ethnic minority, coming from disadvantaged socio-economic strata, having a poor baseline cognitive function, high in mood (depression/anxiety) symptoms, high in specific personality trait (particularly paranoid/schizotypal), and heavy substance use may be risk factors associated with a poorer functioning recovery. These findings are consistent with previous literature which identifies gender (Cotton et al., 2009); ethnic minority status (Hodgekins et al., 2015; Li et al., 2011; Morgan et al., 2008); premorbid adjustment (Addington and Addington, 2005); and personality (Compton et al., 2015; Lysaker et al., 1998; Lysaker and Davis, 2004) as predictors of poor recovery following psychosis. Our results also indicate that substance use history contributes significantly in predicting functioning recovery. 
The identification of four-trajectory solution as the best model accords with both Velthorst et al., 2016 and (Chang et al., 2018), although different analysis approaches were used. Velthorst and colleagues detected four stable trajectories of preserved, moderately, severely, and profoundly impaired social functioning across diagnoses over 20 years follow-up (Velthorst et al., 2016). Given the short-term follow up period in the present study, we were unable to directly compare with Velthorst in terms of long-term trajectory patterns. Chang and colleagues employed the growth mixture modeling (GMM), to explore social-occupational functional trajectories in patients with first-episode non-affective psychosis across 3-year follow-up (Chang et al., 2018). The overall patterns of the 'gradually improved', the 'early improved' and the 'persistently poor' trajectories reported by Chang and colleagues resemble the 'catch-up', 'good outcome', and 'poor outcome' trajectories identified in our study, respectively. However, the 'improved-deteriorated' trajectory identified in Chang et al study was not found in our study. Several reasons might, in part, account for the discrepancy. For example, our sample cohort included both affective and non-affective psychosis patients whereas Chang et al study included only non-affective psychosis patients. GAF score was used in our study whereas SOFAS score was used in Chang et al study. Another report by Hodgekins and colleagues focusing on social functioning recovery in individuals with FEP over a12-month period. These authors found three types of social recovery profile: Low Stable, Moderate-Increasing, and High-Decreasing (Hodgekins et al., 2015). The 'low stable' profile is the most consistent with the 'poor-outcome' trajectory identified in our study. The 'moderate-Increasing', and 'highdecreasing' profiles are different. The present study differs from Hodgekins et al report in many aspects, including functioning assessments (Time use survey vs. GAF) and primary focus in functioning (specific social functioning vs. global impression of functioning). Functional 
outcome represents a multifaceted variable relying on different constructs and depending on several clinical neuropsychological and environmental factors (Bechi et al., 2017). It is likely different patterns of recovery trajectory exist in individuals with FEP depending specific aspect of functional outcome and tools used to assess these functional outcomes.

Several explanations may account for the lack of functional improvement in patients with Poor Outcome trajectory. Patients in this group may have less access to resources, medication, and/or necessary treatment because of being in an unfavorable socio-economic circumstance. In addition, evidence suggests that in the African American population, psychiatric disorders including psychosis have greater stigma attached to them. Blacks with psychiatric disorders are more likely to be viewed as morally inferior which may result in a lessened tendency to adhere to treatment (Alvidrez, 1999). Financial burden, access difficulties, and stigma may reduce patients' access to better treatment and increase their isolation and hopelessness, thereby decreasing or slowing down their recovery (Gary, 2005). Furthermore, personality variables have been linked with patterns of substance abuse (Lysaker and Davis, 2004; Van Os and Jones, 2001), which may impede treatment, worsen cognitive impairment, reduce motivation, and slow down recovery. Finally, it is possible that patients in the poor outcome trajectory may differ neurobiologically (and may represent distinct biotypes) from those in the good outcome categories. This possibility can be empirically tested by longitudinal prospective studies with neuroimaging and electrophysiological studies carried out at baseline.

Our results should be interpreted in light of some limitations. First, the current study focused on short-term functioning trajectory during the first 12 months of psychosis onset. Therefore, it is unclear what happens after the first year in terms of functional recovery. However, one study has shown that the early clinical course is a good predictor for the long-term course (Rund et 
al., 2016). Second, the differences between trajectories were examined using baseline characteristics only. Factors such as engagement with services, family or social support, treatment adherence, or medication use during the follow-up period were not directly assessed. Third, the present study enrolled 369 patients at baseline, only 129 patients' data (35\%) were used for further analysis. Although we did not see any clinical or demographic differences between those with vs without follow-up data, it is possible that this large attrition may impact generalizability of our findings. Finally, as in any exploratory modeling, identification of trajectory classes is affected by sample size. Future study with larger sample is warranted to validate the results.

In summary, we identified four distinct and consistent patterns of functional trajectories across three independent predictors. Individuals with male gender; ethnic minority status; low premorbid adjustment; low executive function/IQ, low SES, personality disorder, substance use history may be risk factors for poor recovery following psychosis. Our findings suggest that functional recovery trajectories appear to be complicated because many psychological and environmental changes occur during the first year after illness onset. Clearly, data driven individual based trajectory analysis can facilitate the understanding of the population heterogeneity and the identification of risk factors associated with poor recovery path. One logical and important next step is to be able to evaluate candidate models that can accurate predict individual level outcomes for improving the quality in personalized treatment and targeted intervention. 


\section{Financial Disclosures}

The authors reported no biomedical financial interests or potential conflicts of interest.

\section{Role of the Funding Source}

This publication was supported by funds received from National Institute of Mental Health grants NIMH MH45156, MH64023 NIH/NCRR/GCRC grant \#M01 RR00056 (MSK). and [R01MH109687]: Mei-Hua Hall, PI; [K24MH104449]: Dost Öngür, PI

Conflict of interest

One of the authors is an editor of this journal. All editorial process for this paper is handled by another editor.

\section{Acknowledgments}

We thank Drs. Nina Schooler, Cameron carter, Raymond Cho, MD, Gretchen Haas PhD, and the clinical core staff of the Center for the Neuroscience of Mental Disorders (David Lewis MD, Director). We thank Kevin Eklund and Elizabeth Radomsky for their assistance in diagnostic, psychopathological and neuropsychological assessments, and Jean Miewald for help in data management.. 
References:

Aas, I.H., 2010. Global Assessment of Functioning (GAF): properties and frontier of current knowledge. Ann Gen Psychiatry 9, 20.

Addington, J., Addington, D., 2005. Patterns of premorbid functioning in first episode psychosis: relationship to 2-year outcome. Acta psychiatrica Scandinavica 112(1), 40-46.

Allen, D.N., Kelley, M.E., Miyatake, R.K., Gurklis, J.A., Jr., van Kammen, D.P., 2001. Confirmation of a two-factor model of premorbid adjustment in males with schizophrenia. Schizophr Bull 27(1), 39-46. Allott, K., Liu, P., Proffitt, T.M., Killackey, E., 2011. Cognition at illness onset as a predictor of later functional outcome in early psychosis: systematic review and methodological critique. Schizophr Res 125(2-3), 221-235.

Alvidrez, J., 1999. Ethnic variations in mental health attitudes and service use among low-income African American, Latina, and European American young women. Community mental health journal 35(6), 515-530.

Ammons, R.B., Ammons, C.H., 1962. The Quick Test (QT): Provisional manual. Psychological Reports 11(1), 111-161.

Andreasen, N.C., Flaum, M., Swayze, V.W., 2nd, Tyrrell, G., Arndt, S., 1990. Positive and negative symptoms in schizophrenia. A critical reappraisal. Arch Gen Psychiatry 47(7), 615-621.

Arabzadeh, S., Amini, H., Tehrani-Doost, M., Sharifi, V., Noroozian, M., Rahiminejad, F., 2014.

Correlation of neurological soft signs and neurocognitive performance in first episode psychosis. Psychiatry Res 220(1-2), 81-88.

Arango, C., Bartko, J.J., Gold, J.M., Buchanan, R.W., 1999. Prediction of neuropsychological performance by neurological signs in schizophrenia. Am J Psychiatry 156(9), 1349-1357. Arnold, S.J., Ivleva, E.I., Gopal, T.A., Reddy, A.P., Jeon-Slaughter, H., Sacco, C.B., Francis, A.N., Tandon, N., Bidesi, A.S., Witte, B., Poudyal, G., Pearlson, G.D., Sweeney, J.A., Clementz, B.A., Keshavan, M.S., Tamminga, C.A., 2015. Hippocampal volume is reduced in schizophrenia and schizoaffective disorder but not in psychotic bipolar I disorder demonstrated by both manual tracing and automated parcellation (FreeSurfer). Schizophr Bull 41(1), 233-249. 
Ayesa-Arriola, R., Rodriguez-Sanchez, J.M., Suero, E.S., Reeves, L.E., Tabares-Seisdedos, R., CrespoFacorro, B., 2016. Diagnosis and neurocognitive profiles in first-episode non-affective psychosis patients. European archives of psychiatry and clinical neuroscience 266(7), 619-628.

Bechi, M., Bosia, M., Spangaro, M., Buonocore, M., Cavedoni, S., Agostoni, G., Bianchi, L., Cocchi, F., Guglielmino, C., Smeraldi, E., Cavallaro, R., 2017. Exploring functioning in schizophrenia: Predictors of functional capacity and real-world behaviour. Psychiatry Res 251, 118-124.

Best, M.W., Gupta, M., Bowie, C.R., Harvey, P.D., 2014. A Longitudinal Examination of the Moderating Effects of Symptoms on the Relationship between Functional Competence and Real World Functional Performance in Schizophrenia. Schizophr Res Cogn 1(2), 90-95.

Bora, E., Akgul, O., Ceylan, D., Ozerdem, A., 2018. Neurological soft signs in bipolar disorder in comparison to healthy controls and schizophrenia: A meta-analysis. European neuropsychopharmacology : the journal of the European College of Neuropsychopharmacology 28(11), 1185-1193.

Bowie, C.R., Depp, C., McGrath, J.A., Wolyniec, P., Mausbach, B.T., Thornquist, M.H., Luke, J., Patterson, T.L., Harvey, P.D., Pulver, A.E., 2010. Prediction of real-world functional disability in chronic mental disorders: a comparison of schizophrenia and bipolar disorder. Am J Psychiatry 167(9), 11161124.

Bucci, P., Mucci, A., Piegari, G., Nobile, M., Pini, S., Rossi, A., Vita, A., Galderisi, S., Maj, M., 2016. Characterization of premorbid functioning during childhood in patients with deficit vs. non-deficit schizophrenia and in their healthy siblings. Schizophr Res 174(1-3), 172-176.

Buchanan, R.W., Heinrichs, D.W., 1989. The Neurological Evaluation Scale (NES): a structured instrument for the assessment of neurological signs in schizophrenia. Psychiatry Res 27(3), 335-350. Cannon, M., Jones, P., Gilvarry, C., Rifkin, L., McKenzie, K., Foerster, A., Murray, R.M., 1997. Premorbid social functioning in schizophrenia and bipolar disorder: similarities and differences. Am J Psychiatry 154(11), 1544-1550.

Cannon, T.D., Chung, Y., He, G., Sun, D., Jacobson, A., van Erp, T.G., McEwen, S., Addington, J., Bearden, C.E., Cadenhead, K., Cornblatt, B., Mathalon, D.H., McGlashan, T., Perkins, D., Jeffries, C., Seidman, L.J., Tsuang, M., Walker, E., Woods, S.W., Heinssen, R., North American Prodrome Longitudinal Study, C., 
2015. Progressive reduction in cortical thickness as psychosis develops: a multisite longitudinal neuroimaging study of youth at elevated clinical risk. Biol Psychiatry 77(2), 147-157.

Cannon-Spoor, H.E., Potkin, S.G., Wyatt, R.J., 1982. Measurement of premorbid adjustment in chronic schizophrenia. Schizophr Bull 8(3), 470-484.

Caplan, B., Zimmet, S.V., Meyer, E.C., Friedman-Yakoobian, M., Monteleone, T., Jude Leung, Y., Guyer, M.E., Rood, L.L., Keshavan, M.S., Seidman, L.J., 2013. Prevention and recovery in early psychosis (PREP((R))): building a public-academic partnership program in Massachusetts, United States. Asian journal of psychiatry 6(2), 171-177.

Carlson, G.A., Kotov, R., Chang, S.W., Ruggero, C., Bromet, E.J., 2012. Early determinants of four-year clinical outcomes in bipolar disorder with psychosis. Bipolar Disord 14(1), 19-30.

Carpenter, W.T., Jr., Kirkpatrick, B., 1988. The heterogeneity of the long-term course of schizophrenia. Schizophr Bull 14(4), 645-652.

Chakos, M.H., Lieberman, J.A., Bilder, R.M., Borenstein, M., Lerner, G., Bogerts, B., Wu, H., Kinon, B., Ashtari, M., 1994. Increase in caudate nuclei volumes of first-episode schizophrenic patients taking antipsychotic drugs. Am J Psychiatry 151(10), 1430-1436.

Chan, R.C., Wang, Y., Wang, L., Chen, E.Y., Manschreck, T.C., Li, Z.J., Yu, X., Gong, Q.Y., 2009. Neurological soft signs and their relationships to neurocognitive functions: a re-visit with the structural equation modeling design. PloS one 4(12), e8469.

Chang, W.C., Chu, A.O.K., Kwong, V.W.Y., Wong, C.S.M., Hui, C.L.M., Chan, S.K.W., Lee, E.H.M., Chen, E.Y.H., 2018. Patterns and predictors of trajectories for social and occupational functioning in patients presenting with first-episode non-affective psychosis: A three-year follow-up study. Schizophr Res. Clementz, B.A., Sweeney, J.A., Hamm, J.P., Ivleva, E.I., Ethridge, L.E., Pearlson, G.D., Keshavan, M.S., Tamminga, C.A., 2016. Identification of Distinct Psychosis Biotypes Using Brain-Based Biomarkers. Am J Psychiatry 173(4), 373-384.

Compton, M.T., Bakeman, R., Alolayan, Y., Balducci, P.M., Bernardini, F., Broussard, B., Crisafio, A., Cristofaro, S., Amar, P., Johnson, S., Wan, C.R., 2015. Personality domains, duration of untreated psychosis, functioning, and symptom severity in first-episode psychosis. Schizophr Res 168(1-2), 113119. 
Cotton, S.M., Lambert, M., Schimmelmann, B.G., Foley, D.L., Morley, K.I., McGorry, P.D., Conus, P., 2009. Gender differences in premorbid, entry, treatment, and outcome characteristics in a treated epidemiological sample of 661 patients with first episode psychosis. Schizophr Res 114(1-3), 17-24. Cross-Disorder Group of the Psychiatric Genomics, C., Lee, S.H., Ripke, S., Neale, B.M., Faraone, S.V., Purcell, S.M., Perlis, R.H., Mowry, B.J., Thapar, A., Goddard, M.E., Witte, J.S., Absher, D., Agartz, I., Akil, H., Amin, F., Andreassen, O.A., Anjorin, A., Anney, R., Anttila, V., Arking, D.E., Asherson, P., Azevedo, M.H., Backlund, L., Badner, J.A., Bailey, A.J., Banaschewski, T., Barchas, J.D., Barnes, M.R., Barrett, T.B., Bass, N., Battaglia, A., Bauer, M., Bayes, M., Bellivier, F., Bergen, S.E., Berrettini, W., Betancur, C., Bettecken, T., Biederman, J., Binder, E.B., Black, D.W., Blackwood, D.H., Bloss, C.S., Boehnke, M., Boomsma, D.I., Breen, G., Breuer, R., Bruggeman, R., Cormican, P., Buccola, N.G., Buitelaar, J.K., Bunney, W.E., Buxbaum, J.D., Byerley, W.F., Byrne, E.M., Caesar, S., Cahn, W., Cantor, R.M., Casas, M., Chakravarti, A., Chambert, K., Choudhury, K., Cichon, S., Cloninger, C.R., Collier, D.A., Cook, E.H., Coon, H., Cormand, B., Corvin, A., Coryell, W.H., Craig, D.W., Craig, I.W., Crosbie, J., Cuccaro, M.L., Curtis, D., Czamara, D., Datta, S., Dawson, G., Day, R., De Geus, E.J., Degenhardt, F., Djurovic, S., Donohoe, G.J., Doyle, A.E., Duan, J., Dudbridge, F., Duketis, E., Ebstein, R.P., Edenberg, H.J., Elia, J., Ennis, S., Etain, B., Fanous, A., Farmer, A.E., Ferrier, I.N., Flickinger, M., Fombonne, E., Foroud, T., Frank, J., Franke, B., Fraser, C., Freedman, R., Freimer, N.B., Freitag, C.M., Friedl, M., Frisen, L., Gallagher, L., Gejman, P.V., Georgieva, L., Gershon, E.S., Geschwind, D.H., Giegling, I., Gill, M., Gordon, S.D., Gordon-Smith, K., Green, E.K., Greenwood, T.A., Grice, D.E., Gross, M., Grozeva, D., Guan, W., Gurling, H., De Haan, L., Haines, J.L., Hakonarson, H., Hallmayer, J., Hamilton, S.P., Hamshere, M.L., Hansen, T.F., Hartmann, A.M., Hautzinger, M., Heath, A.C., Henders, A.K., Herms, S., Hickie, I.B., Hipolito, M., Hoefels, S., Holmans, P.A., Holsboer, F., Hoogendijk, W.J., Hottenga, J.J., Hultman, C.M., Hus, V., Ingason, A., Ising, M., Jamain, S., Jones, E.G., Jones, I., Jones, L., Tzeng, J.Y., Kahler, A.K., Kahn, R.S., Kandaswamy, R., Keller, M.C., Kennedy, J.L., Kenny, E., Kent, L., Kim, Y., Kirov, G.K., Klauck, S.M., Klei, L., Knowles, J.A., Kohli, M.A., Koller, D.L., Konte, B., Korszun, A., Krabbendam, L., Krasucki, R., Kuntsi, J., Kwan, P., Landen, M., Langstrom, N., Lathrop, M., Lawrence, J., Lawson, W.B., Leboyer, M., Ledbetter, D.H., Lee, P.H., Lencz, T., Lesch, K.P., Levinson, D.F., Lewis, C.M., Li, J., Lichtenstein, P., Lieberman, J.A., Lin, D.Y., Linszen, D.H., Liu, C., Lohoff, F.W., Loo, S.K., Lord, C., Lowe, J.K., Lucae, S., MacIntyre, D.J., Madden, P.A., Maestrini, E., Magnusson, P.K., Mahon, P.B., Maier, W., Malhotra, A.K., Mane, S.M., Martin, C.L., 
Martin, N.G., Mattheisen, M., Matthews, K., Mattingsdal, M., McCarroll, S.A., McGhee, K.A., McGough, J.J., McGrath, P.J., McGuffin, P., McInnis, M.G., McIntosh, A., McKinney, R., McLean, A.W., McMahon, F.J., McMahon, W.M., McQuillin, A., Medeiros, H., Medland, S.E., Meier, S., Melle, I., Meng, F., Meyer, J., Middeldorp, C.M., Middleton, L., Milanova, V., Miranda, A., Monaco, A.P., Montgomery, G.W., Moran, J.L., Moreno-De-Luca, D., Morken, G., Morris, D.W., Morrow, E.M., Moskvina, V., Muglia, P., Muhleisen, T.W., Muir, W.J., Muller-Myhsok, B., Murtha, M., Myers, R.M., Myin-Germeys, I., Neale, M.C., Nelson, S.F., Nievergelt, C.M., Nikolov, I., Nimgaonkar, V., Nolen, W.A., Nothen, M.M., Nurnberger, J.I., Nwulia, E.A., Nyholt, D.R., O'Dushlaine, C., Oades, R.D., Olincy, A., Oliveira, G., Olsen, L., Ophoff, R.A., Osby, U., Owen, M.J., Palotie, A., Parr, J.R., Paterson, A.D., Pato, C.N., Pato, M.T., Penninx, B.W., Pergadia, M.L., Pericak-Vance, M.A., Pickard, B.S., Pimm, J., Piven, J., Posthuma, D., Potash, J.B., Poustka, F., Propping, P., Puri, V., Quested, D.J., Quinn, E.M., Ramos-Quiroga, J.A., Rasmussen, H.B., Raychaudhuri, S., Rehnstrom, K., Reif, A., Ribases, M., Rice, J.P., Rietschel, M., Roeder, K., Roeyers, H., Rossin, L., Rothenberger, A., Rouleau, G., Ruderfer, D., Rujescu, D., Sanders, A.R., Sanders, S.J., Santangelo, S.L., Sergeant, J.A., Schachar, R., Schalling, M., Schatzberg, A.F., Scheftner, W.A., Schellenberg, G.D., Scherer, S.W., Schork, N.J., Schulze, T.G., Schumacher, J., Schwarz, M., Scolnick, E., Scott, L.J., Shi, J., Shilling, P.D., Shyn, S.I., Silverman, J.M., Slager, S.L., Smalley, S.L., Smit, J.H., Smith, E.N., Sonuga-Barke, E.J., St Clair, D., State, M., Steffens, M., Steinhausen, H.C., Strauss, J.S., Strohmaier, J., Stroup, T.S., Sutcliffe, J.S., Szatmari, P., Szelinger, S., Thirumalai, S., Thompson, R.C., Todorov, A.A., Tozzi, F., Treutlein, J., Uhr, M., van den Oord, E.J., Van Grootheest, G., Van Os, J., Vicente, A.M., Vieland, V.J., Vincent, J.B., Visscher, P.M., Walsh, C.A., Wassink, T.H., Watson, S.J., Weissman, M.M., Werge, T., Wienker, T.F., Wijsman, E.M., Willemsen, G., Williams, N., Willsey, A.J., Witt, S.H., Xu, W., Young, A.H., Yu, T.W., Zammit, S., Zandi, P.P., Zhang, P., Zitman, F.G., Zollner, S., International Inflammatory Bowel Disease Genetics, C., Devlin, B., Kelsoe, J.R., Sklar, P., Daly, M.J., O'Donovan, M.C., Craddock, N., Sullivan, P.F., Smoller, J.W., Kendler, K.S., Wray, N.R., 2013a. Genetic relationship between five psychiatric disorders estimated from genome-wide SNPs. Nat Genet 45(9), 984-994.

Cross-Disorder Group of the Psychiatric Genomics, C., Smoller, J.W., Craddock, N., Kendler, K., Lee, P.H., Neale, B.M., Nurnberger, J.I., Ripke, S., Santangelo, S., Sullivan, P.F., 2013b. Identification of risk 
loci with shared effects on five major psychiatric disorders: a genome-wide analysis. Lancet 381(9875), 1371-1379.

Curran, P.J., Obeidat, K., Losardo, D., 2010. Twelve Frequently Asked Questions About Growth Curve Modeling. J Cogn Dev 11(2), 121-136.

Dazzan, P., Arango, C., Fleischacker, W., Galderisi, S., Glenthoj, B., Leucht, S., Meyer-Lindenberg, A., Kahn, R., Rujescu, D., Sommer, I., Winter, I., McGuire, P., 2015. Magnetic resonance imaging and the prediction of outcome in first-episode schizophrenia: a review of current evidence and directions for future research. Schizophr Bull 41(3), 574-583.

Flyckt, L., Mattsson, M., Edman, G., Carlsson, R., Cullberg, J., 2006. Predicting 5-year outcome in firstepisode psychosis: construction of a prognostic rating scale. The Journal of clinical psychiatry 67(6), 916-924.

Fountoulakis, K.N., Panagiotidis, P., Gonda, X., Kimiskidis, V., Nimatoudis, I., 2018. Neurological soft signs significantly differentiate schizophrenia patients from healthy controls. Acta Neuropsychiatr 30(2), 97-105.

Gary, F.A., 2005. Stigma: barrier to mental health care among ethnic minorities. Issues Ment Health Nurs 26(10), 979-999.

Genolini, C., Alacoque, X., Sentenac, M., Arnaud, C., 2015. kml and kml3d: R Packages to Cluster Longitudinal Data. Journal of Statistical Software 65(4), 1-25.

Genolini, C., Falissard, B., 2010. KmL: k-means for longitudinal data. Computational Statistics 25(2). Genolini, C., Falissard, B., 2011. KmL: a package to cluster longitudinal data. Comput Methods Programs Biomed 104(3), e112-121.

Genolini, C., Pingault, J.B., Driss, T., Cote, S., Tremblay, R.E., Vitaro, F., Arnaud, C., Falissard, B., 2013. KmL3D: a non-parametric algorithm for clustering joint trajectories. Comput Methods Programs Biomed 109(1), 104-111.

Global Burden of Disease Study, C., 2015. Global, regional, and national incidence, prevalence, and years lived with disability for 301 acute and chronic diseases and injuries in 188 countries, 1990-2013: a systematic analysis for the Global Burden of Disease Study 2013. Lancet 386(9995), 743-800. 
Gonzalez-Blanch, C., Perez-Iglesias, R., Pardo-Garcia, G., Rodriguez-Sanchez, J.M., Martinez-Garcia, O., Vazquez-Barquero, J.L., Crespo-Facorro, B., 2010. Prognostic value of cognitive functioning for global functional recovery in first-episode schizophrenia. Psychol Med 40(6), 935-944.

Green, M.F., 1996. What are the functional consequences of neurocognitive deficits in schizophrenia? Am J Psychiatry 153(3), 321-330.

Green, M.F., Kern, R.S., Braff, D.L., Mintz, J., 2000. Neurocognitive deficits and functional outcome in schizophrenia: are we measuring the "right stuff"? Schizophr Bull 26(1), 119-136.

Gupta, S., Andreasen, N.C., Arndt, S., Flaum, M., Hubbard, W.C., Ziebell, S., 1997. The lowa Longitudinal Study of Recent Onset Psychosis: one-year follow-up of first episode patients. Schizophr Res 23(1), 1-

\section{3.}

Hall, M.-H., Smoller, J.W., 2009. A New Role for Endophenotypes in the GWAS Era: Functional Characterization of Risk Variants Harv Rev Psychiatry In Press.

Hall, M.H., Chen, C.Y., Cohen, B.M., Spencer, K.M., Levy, D.L., Ongur, D., Smoller, J.W., 2015.

Genomewide association analyses of electrophysiological endophenotypes for schizophrenia and psychotic bipolar disorders: a preliminary report. American journal of medical genetics. Part B, Neuropsychiatric genetics : the official publication of the International Society of Psychiatric Genetics 168B(3), 151-161.

Hall, M.H., Levy, D.L., Salisbury, D.F., Haddad, S., Gallagher, P.J., Lohan, M., Cohen, B.M., Ongur, D., Smoller, J.W., 2013. Neurohysiologic Effects of GWAS Derived Schizophrenia and Bipolar Risk Variants. American journal of medical genetics. Part B, Neuropsychiatric genetics : the official publication of the International Society of Psychiatric Genetics.

Hall, M.H., Schulze, K., Rijsdijk, F., Kalidindi, S., McDonald, C., Bramon, E., Murray, R.M., Sham, P., 2009. Are auditory P300 and duration MMN heritable and putative endophenotypes of psychotic bipolar disorder? A Maudsley Bipolar Twin and Family Study. Psychol Med 39(8), 1277-1287.

Hall, M.H., Smoller, J.W., Cook, N.R., Schulze, K., Hyoun Lee, P., Taylor, G., Bramon, E., Coleman, M.J., Murray, R.M., Salisbury, D.F., Levy, D.L., 2012. Patterns of deficits in brain function in bipolar disorder and schizophrenia: a cluster analytic study. Psychiatry Res 200(2-3), 272-280.

Hamilton, M., 1960. A rating scale for depression. Journal of neurology, neurosurgery, and psychiatry $23,56-62$. 
Hegarty, J.D., Baldessarini, R.J., Tohen, M., Waternaux, C., Oepen, G., 1994. One hundred years of schizophrenia: a meta-analysis of the outcome literature. Am J Psychiatry 151(10), 1409-1416.

Herbener, E.S., Harrow, M., 2004. Are negative symptoms associated with functioning deficits in both schizophrenia and nonschizophrenia patients? A 10-year longitudinal analysis. Schizophr Bull 30(4), 813-825.

Hill, S.K., Reilly, J.L., Keefe, R.S., Gold, J.M., Bishop, J.R., Gershon, E.S., Tamminga, C.A., Pearlson, G.D., Keshavan, M.S., Sweeney, J.A., 2013. Neuropsychological impairments in schizophrenia and psychotic bipolar disorder: findings from the Bipolar-Schizophrenia Network on Intermediate Phenotypes (BSNIP) study. Am J Psychiatry 170(11), 1275-1284.

Ho, B.C., Nopoulos, P., Flaum, M., Arndt, S., Andreasen, N.C., 1998. Two-year outcome in first-episode schizophrenia: predictive value of symptoms for quality of life. Am J Psychiatry 155(9), 1196-1201. Hodgekins, J., Birchwood, M., Christopher, R., Marshall, M., Coker, S., Everard, L., Lester, H., Jones, P., Amos, T., Singh, S., Sharma, V., Freemantle, N., Fowler, D., 2015. Investigating trajectories of social recovery in individuals with first-episode psychosis: a latent class growth analysis. The British journal of psychiatry : the journal of mental science 207(6), 536-543.

Honer, W.G., Jones, A.A., Thornton, A.E., Barr, A.M., Procyshyn, R.M., Vila-Rodriguez, F., 2015. Response trajectories to clozapine in a secondary analysis of pivotal trials support using treatment response to subtype schizophrenia. Can J Psychiatry 60(3 Suppl 2), S19-25.

Ivleva, E.I., Morris, D.W., Osuji, J., Moates, A.F., Carmody, T.J., Thaker, G.K., Cullum, M., Tamminga, C.A., 2012. Cognitive endophenotypes of psychosis within dimension and diagnosis. Psychiatry Res 196(1), 38-44.

Jindal, R.D., Keshavan, M.S., 2008. Neurobiology of the early course of schizophrenia. Expert review of neurotherapeutics 8(7), 1093-1100.

Keshavan, M.S., Bagwell, W.W., Haas, G.L., Sweeney, J.A., Schooler, N.R., Pettegrew, J.W., 1994. Changes in caudate volume with neuroleptic treatment. Lancet 344(8934), 1434.

Keshavan, M.S., Clementz, B.A., Pearlson, G.D., Sweeney, J.A., Tamminga, C.A., 2013. Reimagining psychoses: an agnostic approach to diagnosis. Schizophr Res 146(1-3), 10-16. 
Keshavan, M.S., Duggal, H.S., Veeragandham, G., McLaughlin, N.M., Montrose, D.M., Haas, G.L., Schooler, N.R., 2005. Personality dimensions in first-episode psychoses. Am J Psychiatry 162(1), 102109.

Keshavan, M.S., Haas, G., Miewald, J., Montrose, D.M., Reddy, R., Schooler, N.R., Sweeney, J.A., 2003. Prolonged untreated illness duration from prodromal onset predicts outcome in first episode psychoses. Schizophr Bull 29(4), 757-769.

Keshavan, M.S., Schooler, N.R., 1992. First-episode studies in schizophrenia: criteria and characterization. Schizophr Bull 18(3), 491-513.

Keshavan, M.S., Schooler, N.R., Sweeney, J.A., Haas, G.L., Pettegrew, J.W., 1998. Research and treatment strategies in first-episode psychoses. The Pittsburgh experience. Br J Psychiatry Suppl $172(33), 60-65$.

Lehman, A.F., Lieberman, J.A., Dixon, L.B., McGlashan, T.H., Miller, A.L., Perkins, D.O., Kreyenbuhl, J., American Psychiatric, A., Steering Committee on Practice, G., 2004. Practice guideline for the treatment of patients with schizophrenia, second edition. Am J Psychiatry 161(2 Suppl), 1-56. Lenzenweger, M.F., 1999. Deeper into the schizotypy taxon: on the robust nature of maximum covariance analysis. Journal of abnormal psychology 108(1), 182-187.

Lenzenweger, M.F., Lane, M.C., Loranger, A.W., Kessler, R.C., 2007. DSM-IV personality disorders in the National Comorbidity Survey Replication. Biol Psychiatry 62(6), 553-564.

Lenzenweger, M.F., Loranger, A.W., Korfine, L., Neff, C., 1997. Detecting personality disorders in a nonclinical population. Application of a 2-stage procedure for case identification. Arch Gen Psychiatry $54(4), 345-351$.

Levine, S.Z., Rabinowitz, J., Ascher-Svanum, H., Faries, D.E., Lawson, A.H., 2011. Extent of attaining and maintaining symptom remission by antipsychotic medication in the treatment of chronic schizophrenia: evidence from the CATIE study. Schizophr Res 133(1-3), 42-46.

Li, H., Eack, S.M., Montrose, D.M., Miewald, J.M., Keshavan, M., 2011. Longitudinal treatment outcome of African American and Caucasian patients with first episode psychosis. Asian journal of psychiatry 4(4), 266-271. 
Loranger, A.W., Lenzenweger, M.F., Gartner, A.F., Susman, V.L., Herzig, J., Zammit, G.K., Gartner, J.D., Abrams, R.C., Young, R.C., 1991. Trait-state artifacts and the diagnosis of personality disorders. Arch Gen Psychiatry 48(8), 720-728.

Lysaker, P.H., Bell, M.D., Kaplan, E., Bryson, G., 1998. Personality and psychosocial dysfunction in schizophrenia: the association of extraversion and neuroticism to deficits in work performance. Psychiatry Res 80(1), 61-68.

Lysaker, P.H., Davis, L.W., 2004. Social function in schizophrenia and schizoaffective disorder: associations with personality, symptoms and neurocognition. Health Qual Life Outcomes 2, 15. Mathew, I., Gardin, T.M., Tandon, N., Eack, S., Francis, A.N., Seidman, L.J., Clementz, B., Pearlson, G.D., Sweeney, J.A., Tamminga, C.A., Keshavan, M.S., 2014. Medial temporal lobe structures and hippocampal subfields in psychotic disorders: findings from the Bipolar-Schizophrenia Network on Intermediate Phenotypes (B-SNIP) study. JAMA Psychiatry 71(7), 769-777.

McGlashan, T.H., Fenton, W.S., 1992. The positive-negative distinction in schizophrenia. Review of natural history validators. Arch Gen Psychiatry 49(1), 63-72.

Menezes, N.M., Arenovich, T., Zipursky, R.B., 2006. A systematic review of longitudinal outcome studies of first-episode psychosis. Psychol Med 36(10), 1349-1362.

Mohr, F., Hubmann, W., Albus, M., Franz, U., Hecht, S., Scherer, J., Binder, J., Sobizack, N., 2003. Neurological soft signs and neuropsychological performance in patients with first episode schizophrenia. Psychiatry Res 121(1), 21-30.

Morgan, C., Kirkbride, J., Hutchinson, G., Craig, T., Morgan, K., Dazzan, P., Boydell, J., Doody, G.A., Jones, P.B., Murray, R.M., Leff, J., Fearon, P., 2008. Cumulative social disadvantage, ethnicity and firstepisode psychosis: a case-control study. Psychol Med 38(12), 1701-1715.

Muth'en, B., 2004. Latent variable analysis: growth mixture modeling and related techniques for longitudinal data, in: Kaplan, D. (Ed.), Handbook of Quantitative Methodology for the Social Sciences,. Sage, Newbury Park, CA, pp. 345-368.

Nagin, D.S., Odgers, C.L., 2010. Group-based trajectory modeling in clinical research. Annual review of clinical psychology 6, 109-138. 
Overall, J.E., Gorham, D.R., 1962. The brief psychiatric rating scale. Psychological Reports Psychological Reports 10.

Pantelis, C., Yucel, M., Wood, S.J., Velakoulis, D., Sun, D., Berger, G., Stuart, G.W., Yung, A., Phillips, L., McGorry, P.D., 2005. Structural brain imaging evidence for multiple pathological processes at different stages of brain development in schizophrenia. Schizophr Bull 31(3), 672-696.

Pingault, J.B., Cote, S.M., Lacourse, E., Galera, C., Vitaro, F., Tremblay, R.E., 2013. Childhood hyperactivity, physical aggression and criminality: a 19-year prospective population-based study. PloS one 8(5), e62594.

Prasad, K.M., Sahni, S.D., Rohm, B.R., Keshavan, M.S., 2005. Dorsolateral prefrontal cortex morphology and short-term outcome in first-episode schizophrenia. Psychiatry Res 140(2), 147-155.

Prasad, K.M., Sanders, R., Sweeney, J., Montrose, D., Diwadkar, V., Dworakowski, D., Miewald, J., Keshavan, M., 2009. Neurological abnormalities among offspring of persons with schizophrenia: relation to premorbid psychopathology. Schizophr Res 108(1-3), 163-169.

Prikryl, R., Ceskova, E., Kasparek, T., Kucerova, H., 2007. Neurological soft signs and their relationship to 1-year outcome in first-episode schizophrenia. European psychiatry : the journal of the Association of European Psychiatrists 22(8), 499-504.

Robinson, D.G., Woerner, M.G., McMeniman, M., Mendelowitz, A., Bilder, R.M., 2004. Symptomatic and functional recovery from a first episode of schizophrenia or schizoaffective disorder. Am J Psychiatry 161(3), 473-479.

Ruderfer, D.M., Fanous, A.H., Ripke, S., McQuillin, A., Amdur, R.L., Schizophrenia Working Group of Psychiatric Genomics, C., Bipolar Disorder Working Group of Psychiatric Genomics, C., Cross-Disorder Working Group of Psychiatric Genomics, C., Gejman, P.V., O'Donovan, M.C., Andreassen, O.A., Djurovic, S., Hultman, C.M., Kelsoe, J.R., Jamain, S., Landen, M., Leboyer, M., Nimgaonkar, V., Nurnberger, J., Smoller, J.W., Craddock, N., Corvin, A., Sullivan, P.F., Holmans, P., Sklar, P., Kendler, K.S., 2014. Polygenic dissection of diagnosis and clinical dimensions of bipolar disorder and schizophrenia. Mol Psychiatry 19(9), 1017-1024.

Rund, B.R., Barder, H.E., Evensen, J., Haahr, U., ten Velden Hegelstad, W., Joa, I., Johannessen, J.O., Langeveld, J., Larsen, T.K., Melle, I., Opjordsmoen, S., Rossberg, J.I., Simonsen, E., Sundet, K., Vaglum, 
P., McGlashan, T., Friis, S., 2016. Neurocognition and Duration of Psychosis: A 10-year Follow-up of First-Episode Patients. Schizophr Bull 42(1), 87-95.

Sanders, R.D., Joo, Y.H., Almasy, L., Wood, J., Keshavan, M.S., Pogue-Geile, M.F., Gur, R.C., Gur, R.E., Nimgaonkar, V.L., 2006. Are neurologic examination abnormalities heritable? A preliminary study. Schizophr Res 86(1-3), 172-180.

Sanders, R.D., Keshavan, M.S., Forman, S.D., Pieri, J.N., McLaughlin, N., Allen, D.N., van Kammen, D.P., Goldstein, G., 2000. Factor structure of neurologic examination abnormalities in unmedicated schizophrenia. Psychiatry Res 95(3), 237-243.

Sanders, R.D., Keshavan, M.S., Schooler, N.R., 1994. Neurological examination abnormalities in neuroleptic-naive patients with first-break schizophrenia: preliminary results. Am J Psychiatry 151(8), 1231-1233.

Schwarzkopf, S.B., Olson, S.C., Coffman, J.A., Nasrallah, H.A., 1990. Third and lateral ventricular volumes in schizophrenia: support for progressive enlargement of both structures.

Psychopharmacology bulletin 26(3), 385-391.

Sewell, R.A., Perry, E.B., Jr., Karper, L.P., Bell, M.D., Lysaker, P., Goulet, J.L., Brenner, L., Erdos, J., d'Souza, D.C., Seibyl, J.P., Krystal, J.H., 2010. Clinical significance of neurological soft signs in schizophrenia: factor analysis of the Neurological Evaluation Scale. Schizophr Res 124(1-3), 1-12. Shah, J., Eack, S.M., Montrose, D.M., Tandon, N., Miewald, J.M., Prasad, K.M., Keshavan, M.S., 2012. Multivariate prediction of emerging psychosis in adolescents at high risk for schizophrenia. Schizophr Res 141(2-3), 189-196.

Sklar, P., Ripke, S., Scott, L.J., Andreassen, O.A., Cichon, S., Craddock, N., Edenberg, H.J., Nurnberger, J.I., Jr., Rietschel, M., Blackwood, D., Corvin, A., Flickinger, M., Guan, W., Mattingsdal, M., McQuillin, A., Kwan, P., Wienker, T.F., Daly, M., Dudbridge, F., Holmans, P.A., Lin, D., Burmeister, M., Greenwood, T.A., Hamshere, M.L., Muglia, P., Smith, E.N., Zandi, P.P., Nievergelt, C.M., McKinney, R., Shilling, P.D., Schork, N.J., Bloss, C.S., Foroud, T., Koller, D.L., Gershon, E.S., Liu, C., Badner, J.A., Scheftner, W.A., Lawson, W.B., Nwulia, E.A., Hipolito, M., Coryell, W., Rice, J., Byerley, W., McMahon, F.J., Schulze, T.G., Berrettini, W., Lohoff, F.W., Potash, J.B., Mahon, P.B., McInnis, M.G., Zollner, S., Zhang, P., Craig, D.W., Szelinger, S., Barrett, T.B., Breuer, R., Meier, S., Strohmaier, J., Witt, S.H., Tozzi, F., Farmer, A., McGuffin, P., Strauss, J., Xu, W., Kennedy, J.L., Vincent, J.B., Matthews, K., Day, R., Ferreira, M.A., 
O'Dushlaine, C., Perlis, R., Raychaudhuri, S., Ruderfer, D., Hyoun, P.L., Smoller, J.W., Li, J., Absher, D., Thompson, R.C., Meng, F.G., Schatzberg, A.F., Bunney, W.E., Barchas, J.D., Jones, E.G., Watson, S.J., Myers, R.M., Akil, H., Boehnke, M., Chambert, K., Moran, J., Scolnick, E., Djurovic, S., Melle, I., Morken, G., Gill, M., Morris, D., Quinn, E., Muhleisen, T.W., Degenhardt, F.A., Mattheisen, M., Schumacher, J., Maier, W., Steffens, M., Propping, P., Nothen, M.M., Anjorin, A., Bass, N., Gurling, H., Kandaswamy, R., Lawrence, J., McGhee, K., McIntosh, A., McLean, A.W., Muir, W.J., Pickard, B.S., Breen, G., St Clair, D., Caesar, S., Gordon-Smith, K., Jones, L., Fraser, C., Green, E.K., Grozeva, D., Jones, I.R., Kirov, G., Moskvina, V., Nikolov, I., O'Donovan, M.C., Owen, M.J., Collier, D.A., Elkin, A., Williamson, R., Young, A.H., Ferrier, I.N., Stefansson, K., Stefansson, H., Thornorgeirsson, T., Steinberg, S., Gustafsson, O., Bergen, S.E., Nimgaonkar, V., Hultman, C., Landen, M., Lichtenstein, P., Sullivan, P., Schalling, M., Osby, U., Backlund, L., Frisen, L., Langstrom, N., Jamain, S., Leboyer, M., Etain, B., Bellivier, F., Petursson, H., Sigur Sson, E., Muller-Mysok, B., Lucae, S., Schwarz, M., Schofield, P.R., Martin, N., Montgomery, G.W., Lathrop, M., Oskarsson, H., Bauer, M., Wright, A., Mitchell, P.B., Hautzinger, M., Reif, A., Kelsoe, J.R., Purcell, S.M., 2011. Large-scale genome-wide association analysis of bipolar disorder identifies a new susceptibility locus near ODZ4. Nat Genet 43(10), 977-983.

Smith, T.E., Hull, J.W., Huppert, J.D., Silverstein, S.M., 2002. Recovery from psychosis in schizophrenia and schizoaffective disorder: symptoms and neurocognitive rate-limiters for the development of social behavior skills. Schizophr Res 55(3), 229-237.

Strauss, G.P., Harrow, M., Grossman, L.S., Rosen, C., 2010. Periods of recovery in deficit syndrome schizophrenia: a 20-year multi-follow-up longitudinal study. Schizophr Bull 36(4), 788-799.

Subtil, F., Boussari, O., Bastard, M., Etard, J.F., Ecochard, R., Genolini, C., 2017. An alternative classification to mixture modeling for longitudinal counts or binary measures. Stat Methods Med Res $26(1), 453-470$.

Tamminga, C.A., Pearlson, G., Keshavan, M., Sweeney, J., Clementz, B., Thaker, G., 2014. Bipolar and schizophrenia network for intermediate phenotypes: outcomes across the psychosis continuum. Schizophr Bull 40 Suppl 2, S131-137.

Tohen, M., Strakowski, S.M., Zarate, C., Jr., Hennen, J., Stoll, A.L., Suppes, T., Faedda, G.L., Cohen, B.M., Gebre-Medhin, P., Baldessarini, R.J., 2000. The McLean-Harvard first-episode project: 6-month 
symptomatic and functional outcome in affective and nonaffective psychosis. Biol Psychiatry 48(6), 467-476.

Twisk, J., de Vente, W., 2002. Attrition in longitudinal studies. How to deal with missing data. J Clin Epidemiol 55(4), 329-337.

Van Os, J., Jones, P.B., 2001. Neuroticism as a risk factor for schizophrenia. Psychol Med 31(6), 11291134.

Velthorst, E., Fett, A.J., Reichenberg, A., Perlman, G., van Os, J., Bromet, E.J., Kotov, R., 2016. The 20Year Longitudinal Trajectories of Social Functioning in Individuals With Psychotic Disorders. Am J Psychiatry, appiajp201615111419.

Venkatasubramanian, G., Gangadhar, B.N., Jayakumar, P.N., Janakiramaiah, N., Keshavan, M.S., $2003 a$. Reduced Caudate Volume in Never-Treated Schizophrenia : Evidence for Neuro developmental Etiopathogenesis. Indian J Psychiatry 45(2), 20-26.

Venkatasubramanian, G., Latha, V., Gangadhar, B.N., Janakiramaiah, N., Subbakrishna, D.K., Jayakumar, P.N., Keshavan, M.S., 2003b. Neurological soft signs in never-treated schizophrenia. Acta psychiatrica Scandinavica 108(2), 144-146.

Ventura, J., Hellemann, G.S., Thames, A.D., Koellner, V., Nuechterlein, K.H., 2009. Symptoms as mediators of the relationship between neurocognition and functional outcome in schizophrenia: a meta-analysis. Schizophr Res 113(2-3), 189-199.

Verma, S., Subramaniam, M., Abdin, E., Poon, L.Y., Chong, S.A., 2012. Symptomatic and functional remission in patients with first-episode psychosis. Acta psychiatrica Scandinavica 126(4), 282-289. 
Table 1. Socio-demographic and clinical Characteristics of Subject Groups

\begin{tabular}{|c|c|c|c|}
\hline & $\begin{array}{l}\text { Baseline } \\
(n=369)\end{array}$ & $\begin{array}{l}\text { 1-yr Follow-up } \\
(\mathrm{n}=129)\end{array}$ & $\begin{array}{l}\text { Baseline vs. } \\
\text { Follow-up }\end{array}$ \\
\hline Age, yrs & $24.29(7.51)$ & $24.42(7.4)$ & $\mathrm{t}=-\mathbf{0 . 1 7}, \mathrm{p}=\mathbf{0 . 8 7}$ \\
\hline Female sex, $\mathrm{N}(\%)$ & $140(37.9)$ & $46(35.6)$ & $\chi=0.21, p=0.65$ \\
\hline Race (White, AA, others) & $213,128,28$ & $76,41,12$ & $\chi=0.61, p=0.74$ \\
\hline Education, yrs & $12.74(3.1)$ & $13.20(3.2)$ & $\mathrm{t}=-1.44, p=0.15$ \\
\hline SES-Patient & $29.36(13.6)$ & $30.57(13.5)$ & $\mathrm{t}=-\mathbf{0 . 8 4}, \mathrm{p}=0.40$ \\
\hline SES-parent & $41.31(13.5)$ & $41.79(13.8)$ & $\mathrm{t}=-\mathbf{0 . 3 0}, \mathrm{p}=\mathbf{0 . 7 6}$ \\
\hline IQ & $101.06(14.1)$ & $103.14(13.7)$ & $\mathrm{t}=-1.39, \mathrm{p}=\mathbf{0 . 1 7}$ \\
\hline \multicolumn{4}{|l|}{ Clinical } \\
\hline Duration of prodromal, wks & $186.6(233.7)$ & $174.6(223.0)$ & $\mathrm{t}=0.50, p=0.62$ \\
\hline Diagnosis (SZ/SA, Affective & 221,144 & 88,41 & $\chi=0.37, p=0.55$ \\
\hline \multicolumn{4}{|l|}{ Psychosis) } \\
\hline Age of symptom onset & $22.65(7.8)$ & $22.85(7.7)$ & $\mathrm{t}=-\mathbf{0 . 2 5}, \mathrm{p}=\mathbf{0 . 8 0}$ \\
\hline BPRS total & $49.42(9.97)$ & $49.14(10.2)$ & $\mathrm{t}=-\mathbf{0 . 2 7}, \mathrm{p}=\mathbf{0 . 7 9}$ \\
\hline
\end{tabular}




\begin{tabular}{|c|c|c|c|}
\hline HRSD total & $22.0(10.2)$ & $22.31(10.7)$ & $t=-0.26, p=0.79$ \\
\hline GAF & $34.04(10.21)$ & $33.83(9.5)$ & $\mathrm{t}=0.21, \mathrm{p}=0.84$ \\
\hline Premorbid Adjustment Total & $0.34(0.15)$ & $0.35(0.14)$ & $t=-0.26, p=0.79$ \\
\hline SAPS global total & $8.08(3.6)$ & $8.08(3.7)$ & $\mathrm{t}=0.02, \mathrm{p}=0.99$ \\
\hline SANS global total & $12.50(3.3)$ & $12.21(3.3)$ & $\mathrm{t}=\mathbf{0 . 8 5}, \mathrm{p}=0.40$ \\
\hline
\end{tabular}

Note: Values are means (SD) unless otherwise indicated. Abbreviations: SES: Socio-economic status; SAPS: The Scale for the Assessment of

Positive Symptoms. SANS: The Scale for the Assessment of Negative Symptoms. BPRS: Brief Psychotic Rating Score 18 item total score.

HRSD: Hamilton Rating Scale for Depression. GAF: Global Assessment of Functioning Score. 
Table 2. The four-trajectory model using SANS symptoms as predictor against GAF

\begin{tabular}{|c|c|c|c|c|c|c|}
\hline & $\begin{array}{c}\text { Poor (A) } \\
N=48\end{array}$ & $\begin{array}{l}\text { Middle (B) } \\
\quad N=32\end{array}$ & $\begin{array}{c}\text { Catch-up (C) } \\
N=27\end{array}$ & $\begin{array}{c}\text { Good (D) } \\
N=22\end{array}$ & $\begin{array}{l}\text { Group } \\
\text { Comparison }\end{array}$ & Good vs. Poor \\
\hline $\begin{array}{l}\text { SCZ (\%) } \\
\text { Affective } \\
\text { psychosis (\%) }\end{array}$ & $\begin{array}{l}81 \% \\
19 \%\end{array}$ & $\begin{array}{l}37 \% \\
62 \%\end{array}$ & $\begin{array}{l}70 \% \\
30 \%\end{array}$ & $\begin{array}{l}55 \% \\
45 \%\end{array}$ & $\begin{array}{l}\chi 2=15.58 \\
P=0.001\end{array}$ & $\begin{array}{l}X 2=5.44 \\
P=0.020\end{array}$ \\
\hline SEX Male (\%) & $77 \%$ & $56 \%$ & $55 \%$ & $59 \%$ & $\begin{array}{l}\chi 2=4.68 ; \\
P=0.2\end{array}$ & $\begin{array}{l}\chi 2=2.39 ; \\
P=0.12\end{array}$ \\
\hline White & $48 \%$ & $59 \%$ & $74 \%$ & $64 \%$ & $x^{2}=15.64 ;$ & $x 2=7.62$ \\
\hline AA & $48 \%$ & $31 \%$ & $15 \%$ & $18 \%$ & $P=0.016$ & $P=0.020$ \\
\hline Others & $2 \%$ & $10 \%$ & $11 \%$ & $18 \%$ & & \\
\hline Avg IQ score & $98.68(13)$ & $104.76(15)$ & $105.19(13)$ & $109.06(12)$ & $\begin{array}{l}F=3.19 ; \\
P=0.02\end{array}$ & $\begin{array}{l}t=2.83 \\
P=0.006^{*}\end{array}$ \\
\hline Patient SES & 27 & 32 & 37 & 28.5 & $\begin{array}{l}F=2.69 \\
P=0.049\end{array}$ & $\begin{array}{l}t=0.23 \\
P=0.81\end{array}$ \\
\hline Parent SES & 40 & 41 & 42.5 & 44 & $\begin{array}{l}F=0.36 \\
P=0.78\end{array}$ & $\begin{array}{l}t=1.04 \\
P=0.30\end{array}$ \\
\hline Age onset & $22.12(6.9)$ & $22.61(7.2)$ & $26.39(9.4)$ & $19.16(7.4)$ & $\begin{array}{l}F=4.21 \\
P=0.007\end{array}$ & $\begin{array}{l}t=-1.71 \\
P=0.09\end{array}$ \\
\hline $\begin{array}{l}\text { Substance use } \\
\text { Frequency }\end{array}$ & $49 \%$ & $42 \%$ & $28.5 \%$ & $23.8 \%$ & $\begin{array}{l}\chi 2=5.49 \\
P=0.14\end{array}$ & $\begin{array}{l}X 2=3.84 \\
P=0.05\end{array}$ \\
\hline BPRS-18 items & $52.59(9.8)$ & $46.48(10.2)$ & $50.62(8.8)$ & $43.19(9.7)$ & $\begin{array}{l}F=5.66 ; \\
P=0.001\end{array}$ & $\begin{array}{l}\mathrm{t}=-3.67 \\
\mathrm{P}=0.0005^{*}\end{array}$ \\
\hline HRSM-24 items & $22.36(10.1)$ & $23.5(12.0)$ & $24.44(10.1)$ & $16.81(8.8)$ & $\begin{array}{l}F=1.92 ; \\
P=0.13\end{array}$ & $\begin{array}{l}t=-1.87 \\
P=0.07\end{array}$ \\
\hline $\begin{array}{l}\text { WCST- } \\
\text { perseverative } \\
\text { errors }\end{array}$ & $25.15(12.3)$ & $19.27(13.6)$ & $20.22(13.3)$ & $22.12(23.0)$ & $\begin{array}{l}F=0.64 ; \\
P=0.59\end{array}$ & $\begin{array}{l}t=-0.45 \\
P=0.65\end{array}$ \\
\hline PMAS-CHILD & 0.30 & 0.30 & 0.33 & 0.28 & $\begin{array}{l}F=0.09 \\
P=0.96\end{array}$ & $\begin{array}{l}t=-0.24 \\
P=0.81\end{array}$ \\
\hline PMAS-TOTAL & 0.38 & 0.32 & 0.35 & 0.32 & $\begin{array}{l}F=1.10 ; \\
P=0.35\end{array}$ & $\begin{array}{l}t=-1.61 \\
P=0.12\end{array}$ \\
\hline $\begin{array}{l}\text { Duration of } \\
\text { Prodromal (wk) }\end{array}$ & $148.20(152.9)$ & $215.42(276.3)$ & $147.95(220.4)$ & $210.06(274.8)$ & $\begin{array}{l}F=0.67 \\
P=0.57\end{array}$ & $\begin{array}{l}t=1.13 \\
P=0.26\end{array}$ \\
\hline CLUSTER-A & $16.9(11.2)$ & $14.2(10.1)$ & $9.5(6.3)$ & $9.6(7.5)$ & $\begin{array}{l}F=2.15 ; \\
P=0.10\end{array}$ & $\begin{array}{l}t=-1.99 \\
P=0.056\end{array}$ \\
\hline CLUSTER-B & $5.65(6.7)$ & $15.35(17.2)$ & $5.22(6.3)$ & $7.08(6.9)$ & $\begin{array}{l}F=3.29 \\
P=0.026\end{array}$ & $\begin{array}{l}t=0.55 \\
P=0.59\end{array}$ \\
\hline CLUSTER-C & $9.00(6.3)$ & $8.94(6.2)$ & $6.89(5.5)$ & $5.93(4.5)$ & $\begin{array}{l}F=1.67 ; \\
P=0.18\end{array}$ & $\begin{array}{l}t=-2.11 \\
P=0.04\end{array}$ \\
\hline
\end{tabular}




\section{Figure 1. SANS symptoms as predictor against GAF}
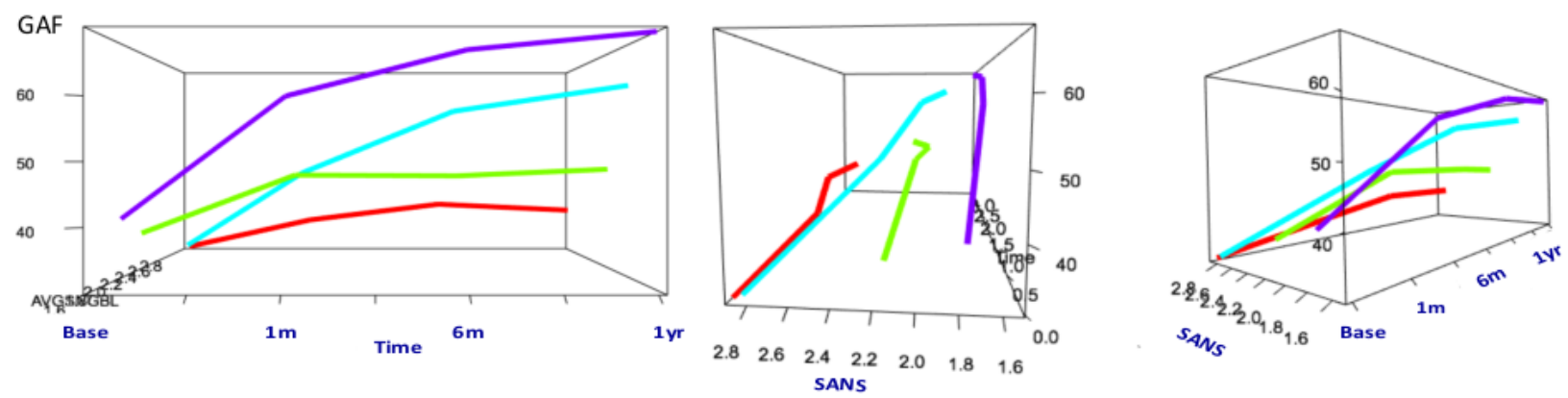

Figure Legend: RED: Poor; Green: Middle; Cyan: Catch-up; Purple: Good 
Table 3. The four-trajectory model using SAPS symptoms as predictor against GAF

\begin{tabular}{|c|c|c|c|c|c|c|}
\hline & $\begin{array}{l}\text { Poor (D) } \\
N=21\end{array}$ & $\begin{array}{l}\text { Middle (A) } \\
N=41\end{array}$ & $\begin{array}{l}\text { Catch-up (C) } \\
N=32\end{array}$ & $\begin{array}{l}\text { Good (B) } \\
N=35\end{array}$ & $\begin{array}{l}\text { Group } \\
\text { Comparison }\end{array}$ & Good vs. Poor \\
\hline \begin{tabular}{|l} 
SCZ \\
Affective \\
Psychosis \\
\end{tabular} & $\begin{array}{l}86 \% \\
14 \%\end{array}$ & $\begin{array}{l}49 \% \\
51 \%\end{array}$ & $\begin{array}{l}78 \% \\
22 \%\end{array}$ & $\begin{array}{l}54 \% \\
46 \%\end{array}$ & $\begin{array}{l}X^{2}=12.55 \\
P=0.006\end{array}$ & $\begin{array}{l}\chi^{2}=5.78 \\
P=0.016^{*}\end{array}$ \\
\hline SEX Male (\%) & $81 \%$ & $71 \%$ & $56 \%$ & $54 \%$ & $\begin{array}{l}X 2=5.71 ; \\
P=0.13\end{array}$ & $\begin{array}{l}X 2=4.07 \\
P=0.04\end{array}$ \\
\hline White & $38 \%$ & $58 \%$ & $66 \%$ & $66 \%$ & $x 2=12.30 ;$ & x2 =7.73; \\
\hline$A A$ & $57 \%$ & $37 \%$ & $22 \%$ & $20 \%$ & $\mathrm{P}=0.06$ & $\mathrm{P}=0.02$ \\
\hline Others & $5 \%$ & $5 \%$ & $12 \%$ & $14 \%$ & & \\
\hline Avg IQ score & $95.14(12.2)$ & $103.1(14.0)$ & $103.3(11.3)$ & $107.6(14.8)$ & $\begin{array}{l}F=3.32 ; \\
P=0.02\end{array}$ & $\begin{array}{l}t=3.02 ; \\
P=0.004^{*}\end{array}$ \\
\hline Patient SES & $30.4(10.8)$ & $25.85(9.9)$ & $36.0(14.3)$ & $31.29(16.3)$ & $\begin{array}{l}F=3.53 ; \\
P=0.02\end{array}$ & $\begin{array}{l}t=0.20 \\
P=0.85\end{array}$ \\
\hline Parent SES & $38.47(13.5)$ & $42.05(13.1)$ & $41.41(15.1)$ & $43.42(13.8)$ & $\begin{array}{l}F=0.44 ; \\
P=0.72\end{array}$ & $\begin{array}{l}t=1.16 \\
P=0.25\end{array}$ \\
\hline Age onset & $24.49(6.9)$ & $21.06(6.4)$ & $24.37(9.0)$ & $22.64(8.1)$ & $\begin{array}{l}F=1.43 ; \\
P=0.24\end{array}$ & $\begin{array}{l}t=-0.83 \\
P=0.41\end{array}$ \\
\hline \begin{tabular}{|l|} 
Substance use \\
Frequency \\
\end{tabular} & $57 \%$ & $35 \%$ & $40 \%$ & $32 \%$ & $\begin{array}{l}X 2=4.20 ; \\
P=0.24\end{array}$ & $\begin{array}{l}X 2=3.28 \\
P=0.07\end{array}$ \\
\hline BPRS-18 items & $58.24(10.2)$ & $45.49(6.3)$ & $55.97(8.3)$ & $42.11(8.0)$ & $\begin{array}{l}F=28.41 ; \\
P<0.0001\end{array}$ & $\begin{array}{l}t=-6.59 \\
P<0.0001 *\end{array}$ \\
\hline HRSM-24 items & $26.08(12.0)$ & $20.84(10.1)$ & $26.11(10.3)$ & $18.59(9.8)$ & $\begin{array}{l}F=0.97 \\
P=0.53\end{array}$ & $\begin{array}{l}t=-2.14 \\
P=0.04\end{array}$ \\
\hline $\begin{array}{l}\text { WCST- } \\
\text { perseverative } \\
\text { errors }\end{array}$ & $29.25(16.0)$ & $21.90(12.5)$ & $20.3(11.5)$ & $19.35(17.7)$ & $\begin{array}{l}F=0.96 \\
P=0.41\end{array}$ & $\begin{array}{l}\mathrm{t}=-1.37 \\
\mathrm{P}=0.18\end{array}$ \\
\hline PMAS-CHILD & $0.27(0.19)$ & $0.29(0.21)$ & $0.31(0.15)$ & $0.34(0.20)$ & $\begin{array}{l}F=0.39 ; \\
P=0.76\end{array}$ & $\begin{array}{l}t=0.93 \\
P=0.36\end{array}$ \\
\hline PMAS-TOTAL & $0.36(0.2)$ & $0.35(0.2)$ & $0.33(0.1)$ & $0.37(0.1)$ & $\begin{array}{l}F=0.26 ; \\
P=0.85\end{array}$ & $\begin{array}{l}t=0.16 \\
P=0.88\end{array}$ \\
\hline \begin{tabular}{|l|} 
Duration of \\
Prodromal (wk)
\end{tabular} & $96.69(101.7)$ & $\begin{array}{l}181.30 \\
(192.1) \\
\end{array}$ & $\begin{array}{l}160.74 \\
(239.7) \\
\end{array}$ & $\begin{array}{l}230.52 \\
(284.2) \\
\end{array}$ & $\begin{array}{l}F=1.54 ; \\
P=0.21\end{array}$ & $\begin{array}{l}t=2.02 \\
P=0.05\end{array}$ \\
\hline CLUSTER-A & $10.67(8.4)$ & $19.27(12.1)$ & $12.88(7.4)$ & $8.05(6.8)$ & $\begin{array}{l}F=4.96 ; \\
P=0.004\end{array}$ & $\begin{array}{l}t=-0.78 \\
P=0.44\end{array}$ \\
\hline CLUSTER-B & $13.50(12.0)$ & $7.53(15.2)$ & $7.28(10.2)$ & $8.79(8.2)$ & $\begin{array}{l}F=0.54 ; \\
P=0.66\end{array}$ & $\begin{array}{l}t=-1.10 \\
P=0.28\end{array}$ \\
\hline CLUSTER-C & $6.33(6.9)$ & $10.00(6.2)$ & $8.36(6.0)$ & $5.75(4.1)$ & $\begin{array}{l}F=1.87 ; \\
P=0.14\end{array}$ & $\begin{array}{l}t=-0.26 \\
P=0.80\end{array}$ \\
\hline
\end{tabular}




\section{Figure 2. SAPS symptoms as predictor against GAF}
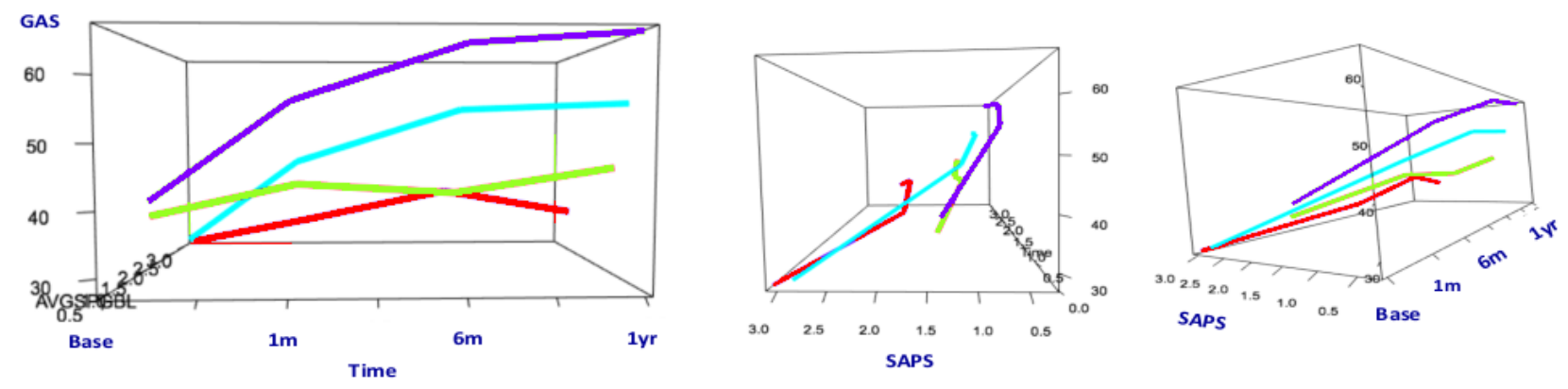

Figure Legend: RED: Poor; Green: Middle; Cyan: Catch-up; Purple: Good 
Table 4. The four-trajectory model using NSS at baseline as predictor against GAF

\begin{tabular}{|c|c|c|c|c|c|c|}
\hline & $\begin{array}{l}\text { Poor (D) } \\
N=21\end{array}$ & $\begin{array}{l}\text { Middle (B) } \\
N=32\end{array}$ & $\begin{array}{l}\text { Catch-up (C) } \\
N=23\end{array}$ & $\begin{array}{l}\text { Good (A) } \\
N=44\end{array}$ & $\begin{array}{l}\text { Group } \\
\text { Comparison }\end{array}$ & Good vs. Poor \\
\hline$S C Z$ & $86 \%$ & $63 \%$ & $70 \%$ & $48 \%$ & $x 2=9.42$ & $\chi 2=8.55$ \\
\hline BPD & $14 \%$ & $37 \%$ & $30 \%$ & $52 \%$ & $P=0.02$ & $P=0.003^{*}$ \\
\hline SEX Male (\%) & $74 \%$ & $58 \%$ & $67 \%$ & $61 \%$ & $\begin{array}{l}\chi 2=2.09 ; \\
P=0.56\end{array}$ & $\begin{array}{l}X 2=1.82 \\
P=0.18\end{array}$ \\
\hline White & $52 \%$ & $50 \%$ & $71 \%$ & $69 \%$ & $\chi^{2}=20.84 ;$ & $\chi 2=4.91 ;$ \\
\hline AA & $43 \%$ & $47 \%$ & $17 \%$ & $17 \%$ & $P=0.05$ & $P=0.09$ \\
\hline Others & $5 \%$ & $3 \%$ & $12 \%$ & $14 \%$ & & \\
\hline Avg IQ score & $89.62(11.07)$ & $103.40(11.9)$ & $100.28(11.0)$ & 111.92 & $\begin{array}{l}F=15.37 \\
P<0.0001\end{array}$ & $\begin{array}{l}t=6.43 \\
P<0.0001 *\end{array}$ \\
\hline Patient SES & $27.2(8.9)$ & $29.5(9.6)$ & $28.4(15.6)$ & $34.4(16.2)$ & $F=1.77 ; P=0.16$ & $\begin{array}{l}t=1.82 \\
P=0.07\end{array}$ \\
\hline Parent SES & $33.3(12.4)$ & $41.0(13.5)$ & $35.8(12.2)$ & $47.4(12.6)$ & $\begin{array}{l}F=6.09 ; \\
P=0.0008\end{array}$ & $\begin{array}{l}t=3.63 \\
P=0.0006 *\end{array}$ \\
\hline Age onset & $25.2(9.6)$ & $21.6(5.5)$ & $21.0(8.3)$ & $23.0(7.7)$ & $F=1.34 ; P=0.27$ & $\begin{array}{l}t=-0.99 \\
P=0.33\end{array}$ \\
\hline Substance use & $48 \%$ & $44 \%$ & $35 \%$ & $30 \%$ & $F=2.71 ; \quad P=0.44$ & $\begin{array}{l}X 2=2.03 ; \\
P=0.15\end{array}$ \\
\hline BPRS-18 items & $52.90(11.2)$ & $51.03(8.0)$ & $48.0(11.9)$ & $45.38(8.7)$ & $F=3.61 ; P=0.01$ & $\begin{array}{l}t=-2.92 ; \\
P=0.005^{*}\end{array}$ \\
\hline HRSM-24 items & 24.0 & $25.71(12.6)$ & $20.0(10.2)$ & $20.63(9.1)$ & $F=1.57 ; P=0.20$ & $\begin{array}{l}t=-1.13 \\
P=0.26\end{array}$ \\
\hline $\begin{array}{l}\text { WCST- } \\
\text { perseverative } \\
\text { errors }\end{array}$ & $32.25(17.6)$ & $22.89(11.3)$ & $24.5(17.7)$ & $14.79(11.6)$ & $F=2.49 ; P=0.07$ & $\begin{array}{l}t=-2.67 \\
P=0.01\end{array}$ \\
\hline PMASCHILD & $0.36(0.2)$ & $0.28(0.2)$ & $0.30(0.2)$ & $0.30(0.1)$ & $F=0.47 ; \quad P=0.70$ & $\begin{array}{l}t=-0.82 \\
P=0.42\end{array}$ \\
\hline PMASTOT & $0.39(0.2)$ & $0.35(0.1)$ & $0.32(0.1)$ & $0.34(0.1)$ & $F=0.55 ; P=0.65$ & $\begin{array}{l}t=-0.99 \\
P=0.33\end{array}$ \\
\hline \begin{tabular}{|l|} 
Duration of \\
Prodromal (wk) \\
\end{tabular} & $124.07(127.2)$ & $212.23(212.8)$ & $173.97(183)$ & $200.06(294.8)$ & $\begin{array}{l}\mathrm{F}=0.72 ; \\
\mathrm{P}=0.54\end{array}$ & $\begin{array}{l}t=1.12 ; \\
P=0.26\end{array}$ \\
\hline CLUSTER-A & $15.7(11.1)$ & $17.07(11.4)$ & $9.0(6.8)$ & $11.31(8.2)$ & $F=2.15 ; P=0.10$ & $\begin{array}{l}t=-1.30 \\
P=0.20\end{array}$ \\
\hline CLUSTER-B & $4.4(3.3)$ & $10.3(12.1)$ & $11.07(11.0)$ & $7.88(12.8)$ & $F=0.80 ; P=0.50$ & $\begin{array}{l}t=0.84 \\
P=0.41\end{array}$ \\
\hline CLUSTER-C & $8.4(6.0)$ & $9.86(6.3)$ & $4.23(3.2)$ & $8.58(5.8)$ & $F=2.63 ; P=0.06$ & $\begin{array}{l}t=0.08 \\
P=0.94\end{array}$ \\
\hline
\end{tabular}




\section{Figure 3. NSS symptoms as predictor against GAF}
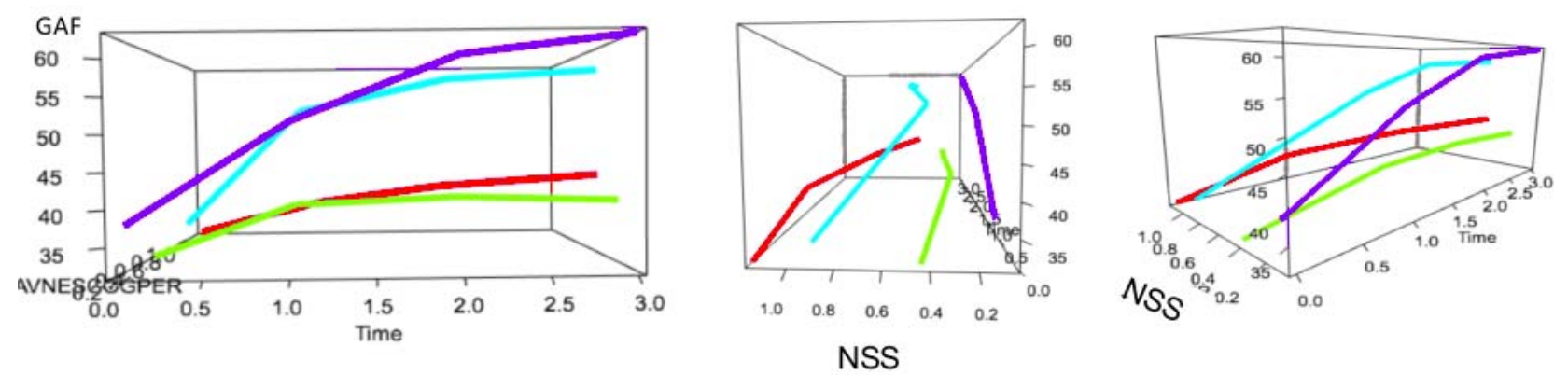

Figure Legend: RED: Poor; Green: Middle; Cyan: Catch-up; Purple: Good 